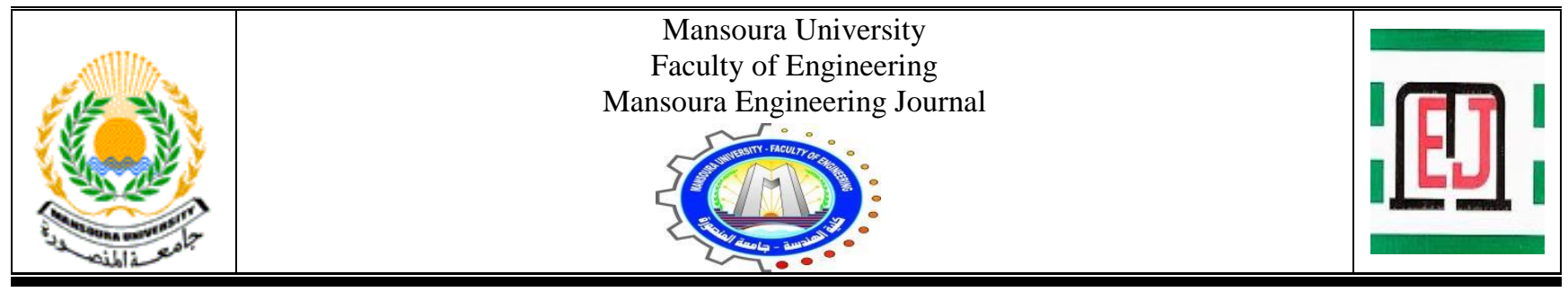

\title{
Thermal Comfort of Educational Spaces in Campus Buildings and its Effect on the Functional Performance Case Study: University of Garmian in the Kurdistan Region of Iraq
}

Chrakhan Ahmed Hama, Sherif Ahmed sheta and Mina Michel wadie samaan

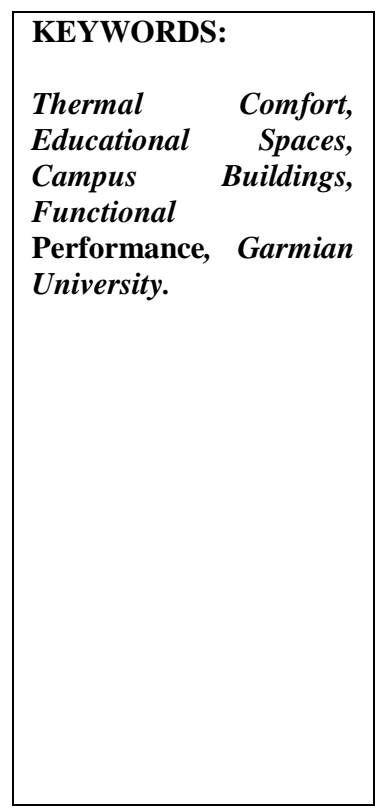

Abstract-The Most important questions about the thermal comfort of educational spaces in campuses and its effect on the functional performance are simple ones. Why this subject important, Developing design standards for university buildings in the region to reach spaces that provide thermal comfort and high functionality, do educational spaces is lack thermal comfort requirements, and what is the effect of thermal comfort on the functionality of university educational buildings?

Only by answering these questions can we develop design parameters to achieve the requirements of thermal comfort for education space users.

The research about thermal comfort of educational spaces in campuses and its effect on the functional performance helps all educational spaces user to arrive to the design criteria and conditions necessary to provide an atmosphere that seeks thermal comfort for the occupants of the educational spaces of the university buildings.

When analyzing the case study, it was found that the educational spaces in the Department of Civil Engineering at Garmian University need a set of design treatments after identifying the exiting problem.

Thermal comfort helps teachers and students focus within the learning spaces while performing lessons.

The intriguing ides expressed in this thesis open the door to questions about how designing university buildings with a higher degree of thermal comfort for their occupants can raise the level of design functionality.

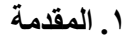

عتبر المبنى الجامعي من أهم أساسيات العملية التعليمية و عاملاً

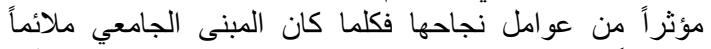

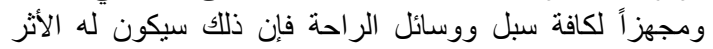

$$
\text { الإيجابي على العملية التعليمية كلها. }
$$

Mina Michel wadie samaan Lecturer at Architectural Engineering Department - Faculty of Engineering - Mansoura University. (e-mail: samaan@mans.edu.eg).

Received: (30 August, 2021) - Revised: (15 September, 2021) - Accepted: (18 September, 2021)

Corresponding Author: Chrakhan Ahmed Hama, (MSc) at Engineer of Architectural Engineering Department - Faculty of Engineering - Mansoura University. (e-mail: yadgarhawalsaz@yahoo.com)

Sherif Ahmed sheta Assistant professor at Architectural Engineering Department - Faculty of Engineering - Mansoura University.

(e-mail: sheriefsheta@mans.edu.eg).

(Ser. NO. BFEMU-2108-1156) 
وتحديد العينة و أساليب جمع البيانات، تعد دراسة: (دينا أحمد محمد حسين:

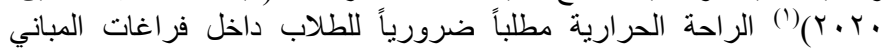

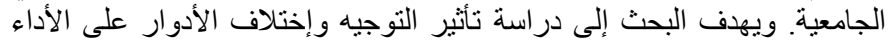

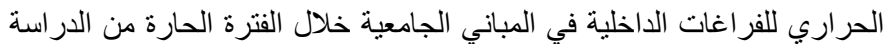

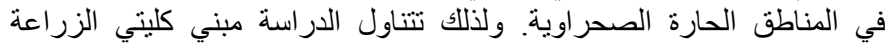

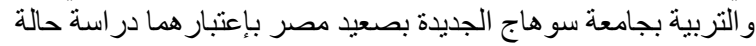

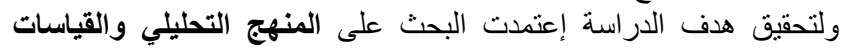

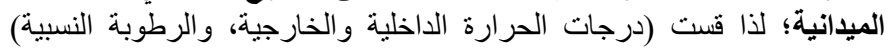

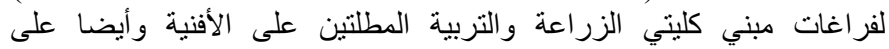

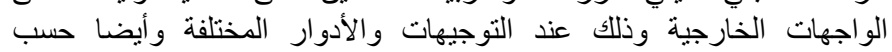

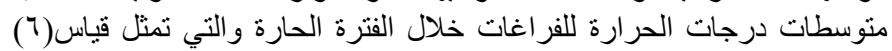

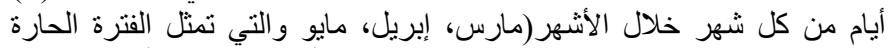

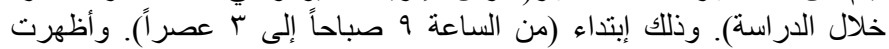

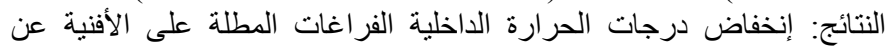

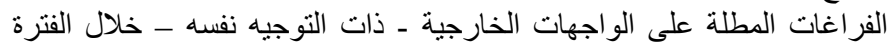

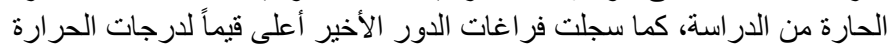

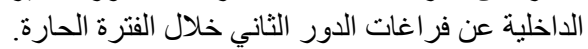

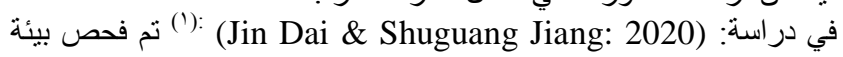
البناء و الر احة الحر ارية لثاغليها في موقع مبنى الجامعة في منطقة مناخية شديدة

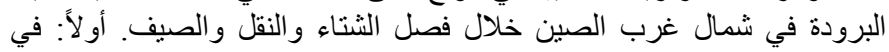

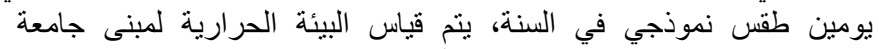
(Shahazi

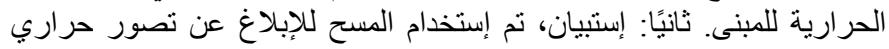

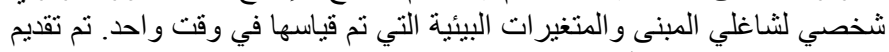

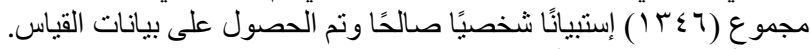

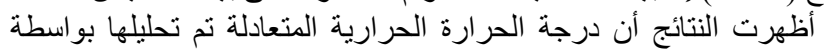

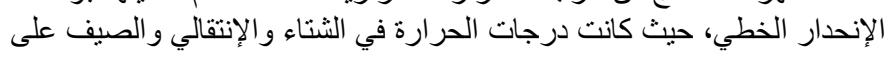

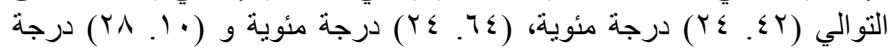

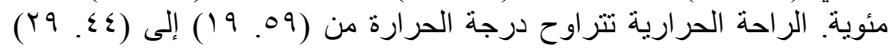

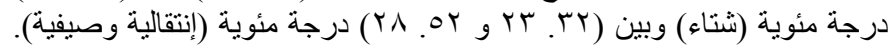

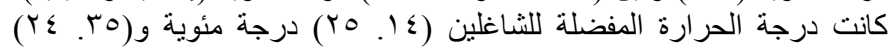

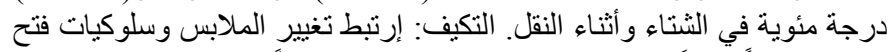

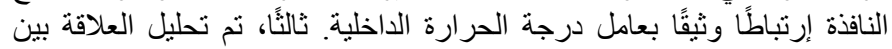

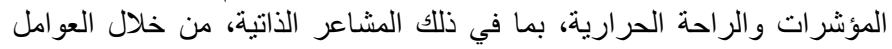

الموضو عية. دراسة: (Binaee Yaseen Raof et al.: 2020):

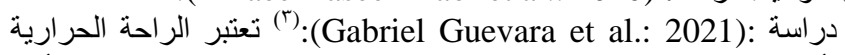

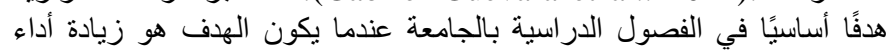

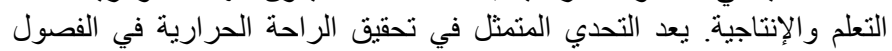

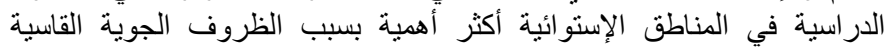

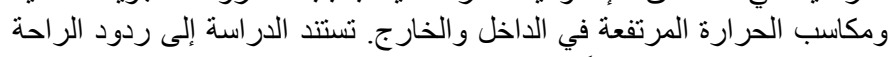

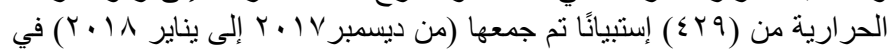

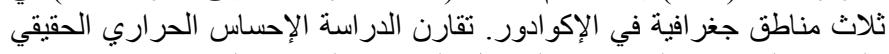

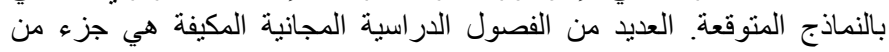

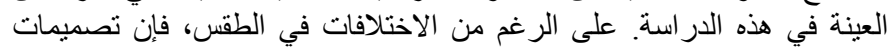

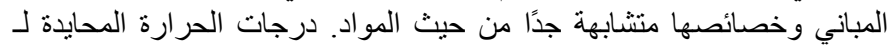

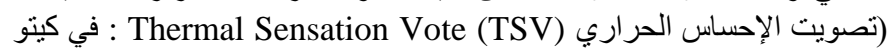

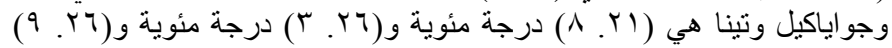

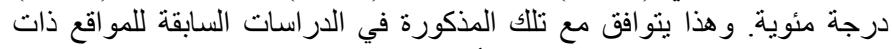

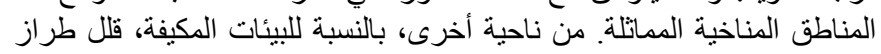

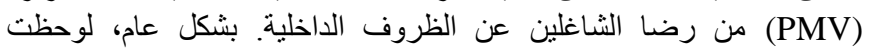

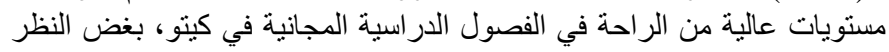

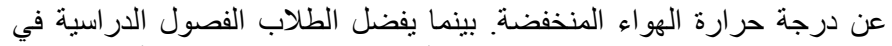

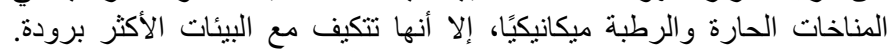

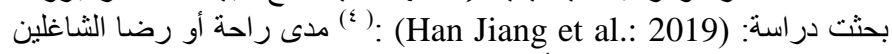

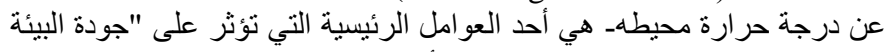

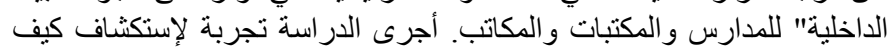

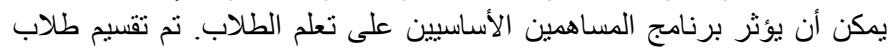

ومع التطور في جميع المجالات ومنها مجال التعليم فقد وجب الإهتمام

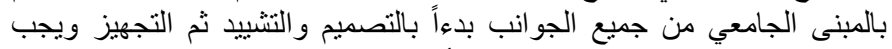

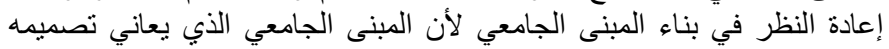

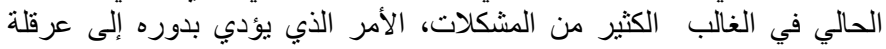

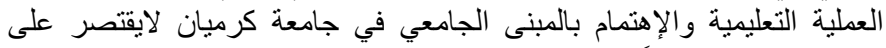

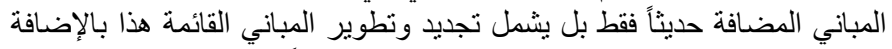

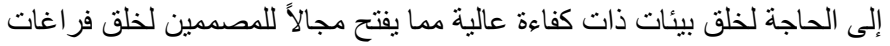

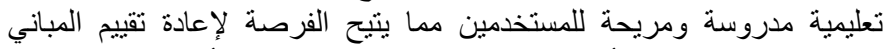

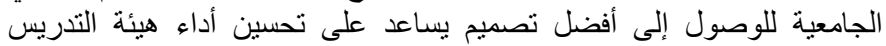

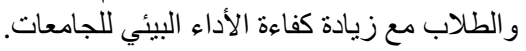

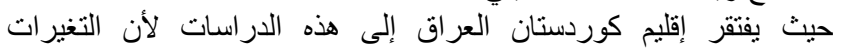

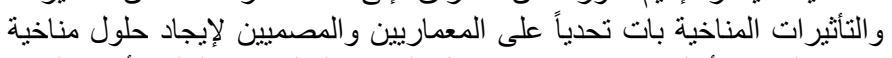

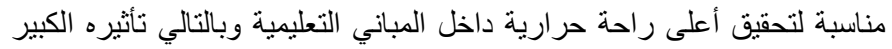

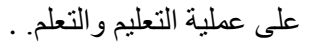

\section{r ب الإجراعات المنهجية للار اسة}

يمكن نستعرض المشكلة الرئيسية للار اسة كالتالي :

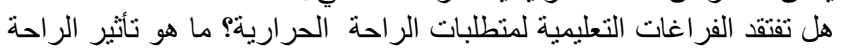

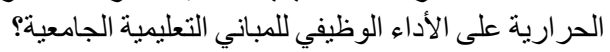

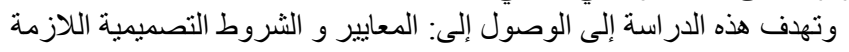

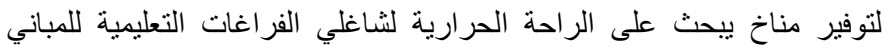
الجامعية في منطقة الدر استة.

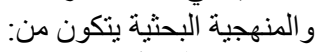

المرحلة الأولى: (الدراسة النظرية) تم تناول الدراسة النظرية وخلفة ولفيات

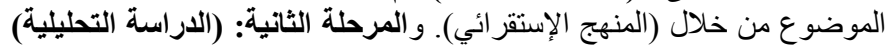

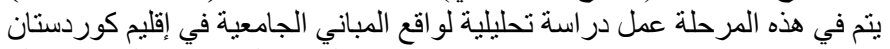

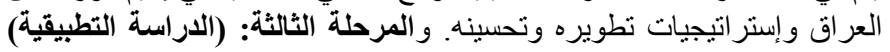

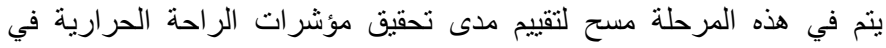

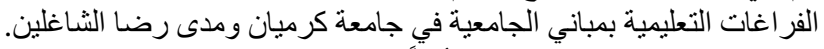

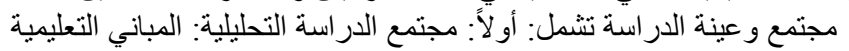

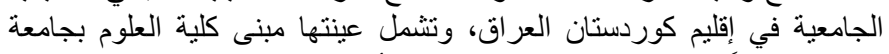

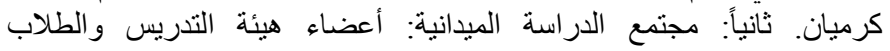

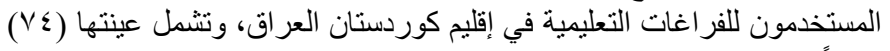
مفرداً. أما بنسبة لحدود الدراسة فيتكون من: الحدود المكانية: مدينة كلار بمحافظة

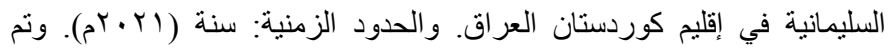

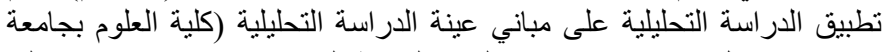

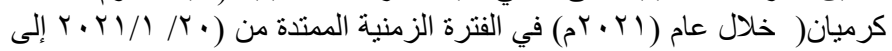

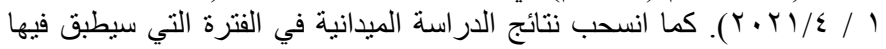

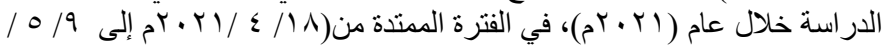
( )

أدوات الدر اسة و أساليب جمع وتحليل البيانات فهي: أولاً: الزيار ات الميدانية

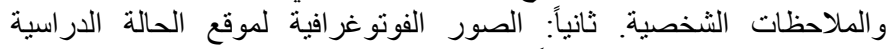

وتفاصيلها بواسطة الباحثة. ثالثاً: إستخدام برنامج (Climate Consultant)

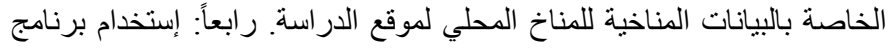

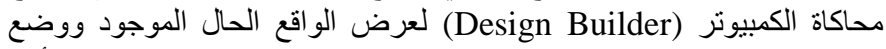

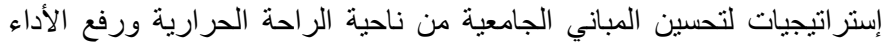

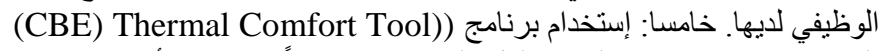
الخاصة بتحديد مناطق الراحة لكل الفراغات. سادساً: إستخدام أجهزة قياسات ميدانية (STATION METEO ARADIOGUIDEE ) لقياس (درجة الخهات الحرارة و الرطوبة النسبية وسرعة الهواء) لفراغات حالة الدراسة. سابعاً:

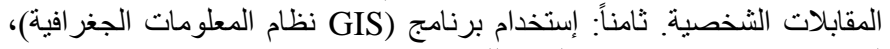

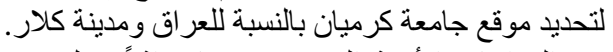

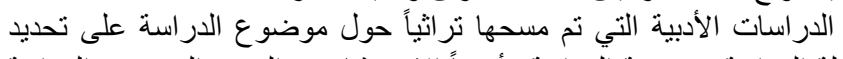

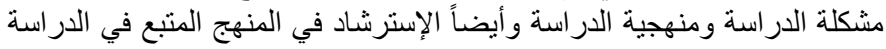


الجنوب و أكثرية التصاميم ملائم للمناخ البارد لذلك المشكلة برزت بشكل كبير جداً في هذه المنطقة. ثالثاً: قرب الباحثة في موقع الدئة الدراسة عن قريب والدراية والملاحظة بوجود المشاكل الموجودة.

Climate ) ب r r r r البيانات المناخية الخاصة بنطقة الدراسة بواسطة برنامج) (Consultant

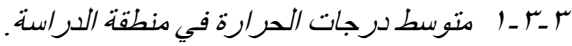

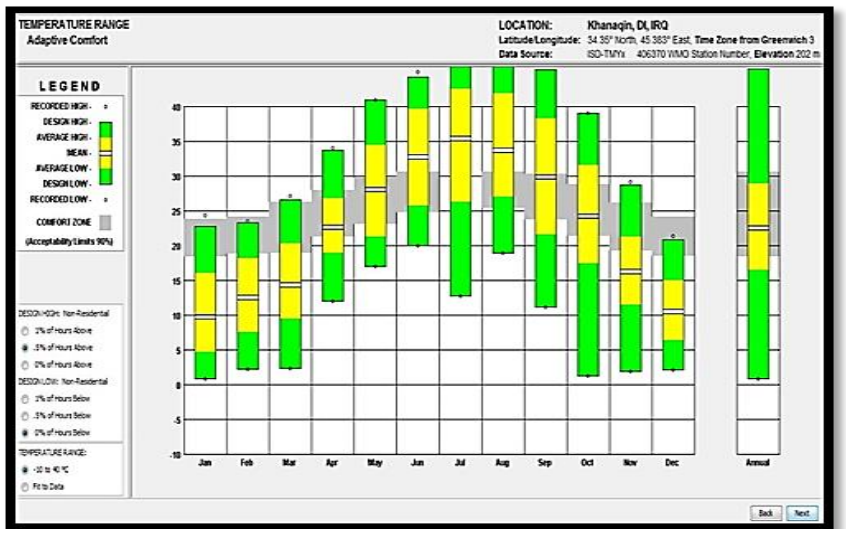

شكل (؟): متوسط درجات الحر ارة في منطقة الدراسة

المرجع: من عمل الباحثة بإستخدام برنامج (Climate Consultant)

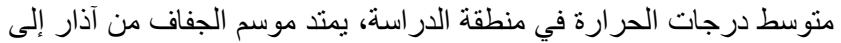

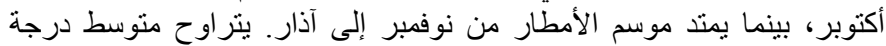

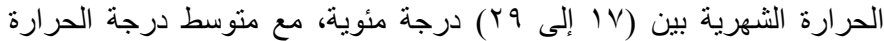

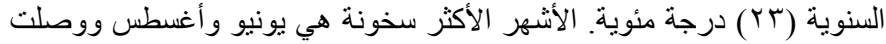

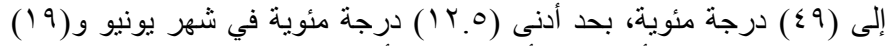

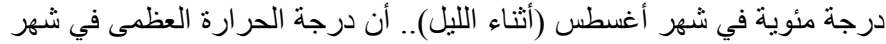

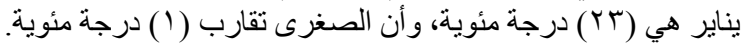
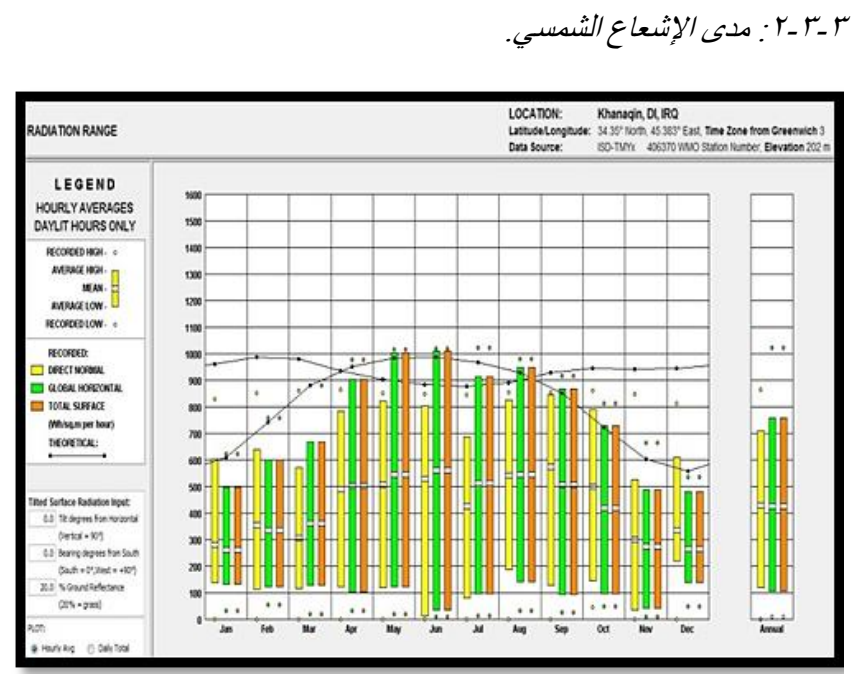

شكل (r)): الإشعاع الثمسي في منطقة الدر اسة.

المرجع: من عمل الباحثة بإنتخدام برنامج (Climate Consultant)

يصل الإشعاع الثمسي العادي المباشر في منطقة الدراسة إلى الحد الأدنى في

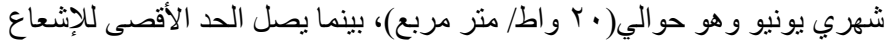

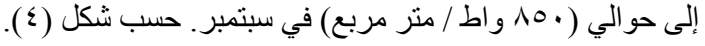

الجامعة (ن = Yo) بشكل عشو ائي إلى ظروف درجات حرارة مختلفة في بيئة

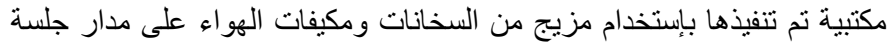

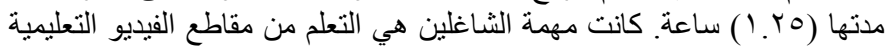

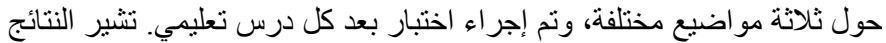

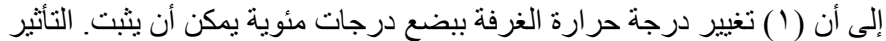

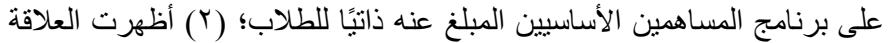

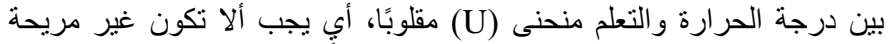

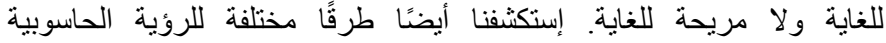

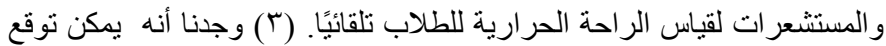

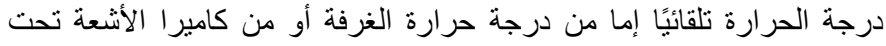

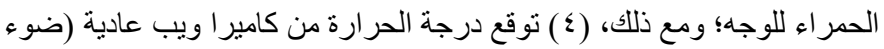

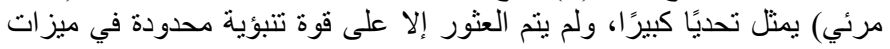

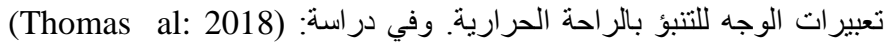

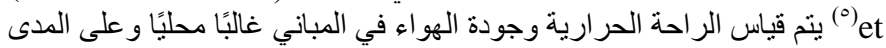

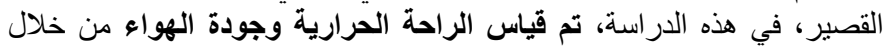

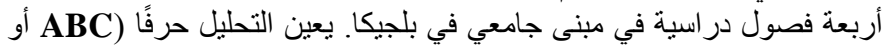

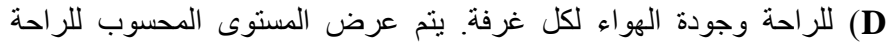

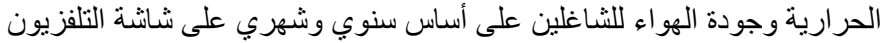

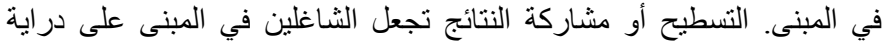

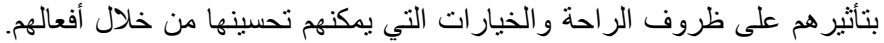

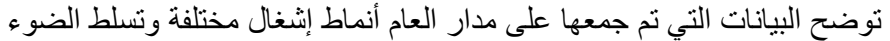

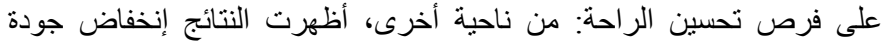
الهو اءه وحدود ثناني أكسيد الكربون.

\section{r. - حالة الدراسة ومبررات إختياره}

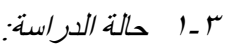

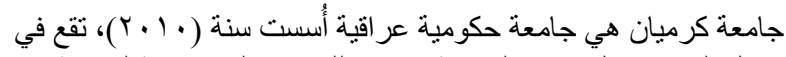

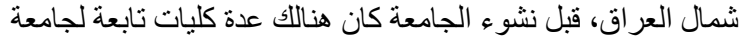

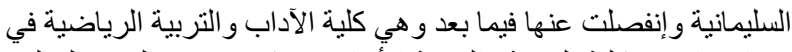

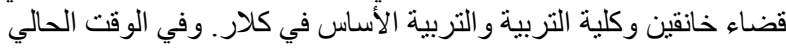

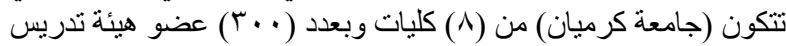

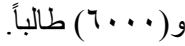

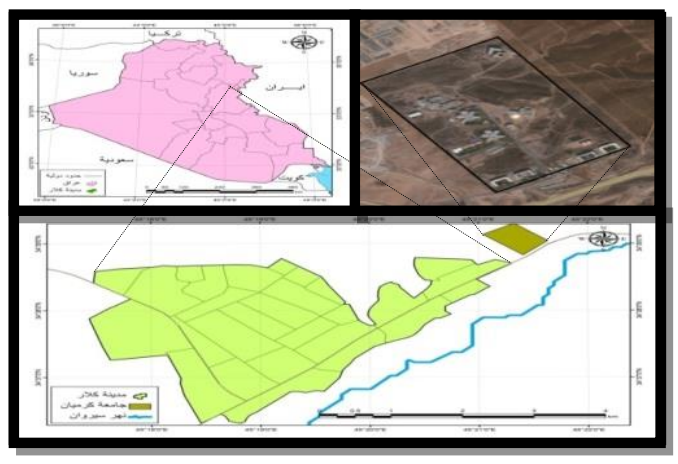

شكل ( ) ): موقع جامعة كرميان بالنسبة للعر اق ومدينة كلار. المرجع: من عمل الباحثة بإستخدام (1) (Arc Map GIS 2020)

r r r r : مبررات إختيار (جامعة كرميان) كعينة للاراسة التحليلية لعدة أسباب، أهمها

أولاً: يعد من إحدى الجامعات الحكومية الجديدة في الإقليم ويحتاج سنوياً إلى فتح

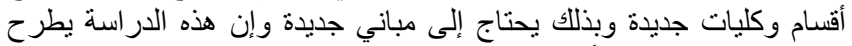

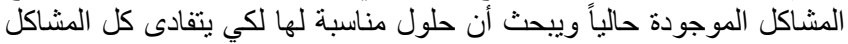

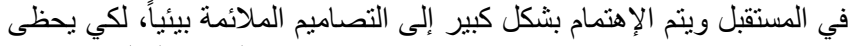
بر احة حرارية جيدة ويرتفع بمستوى إرضاء مستخدية الإندي المباني التعليمية.

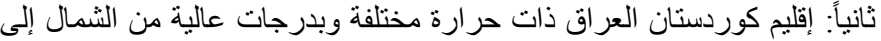




$$
\text { r ــ : تحلبل الفراغات التعليمية بجامعة كرميان. }
$$

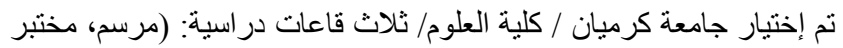

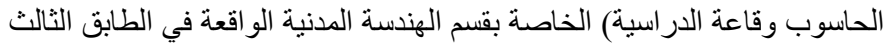

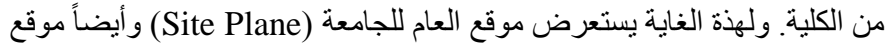

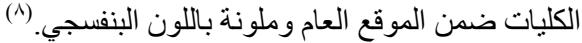

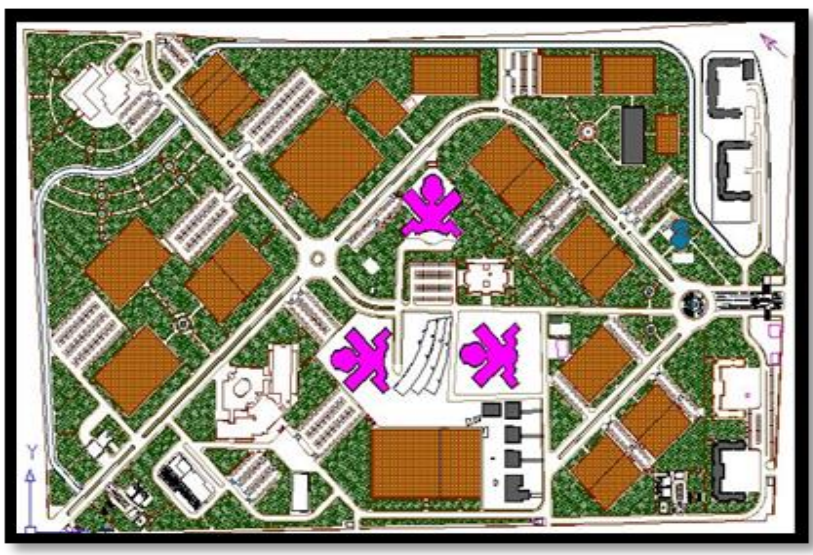

شكل (†): الموقع العام لجامعة كرميان

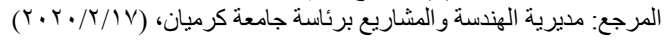

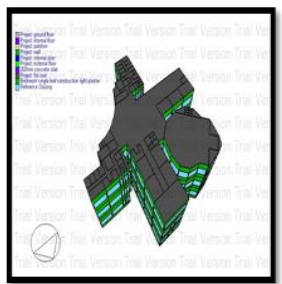

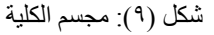

المرجع: مديرية الهندسة

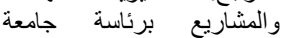

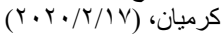

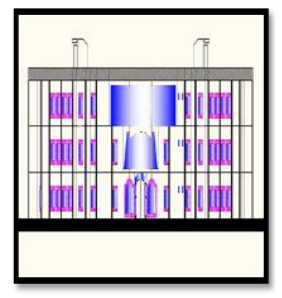

شكل (^): الو اجهة الأمامية للكلية

المرجع: مديرية الهندسة

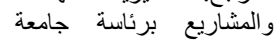

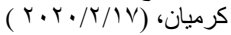

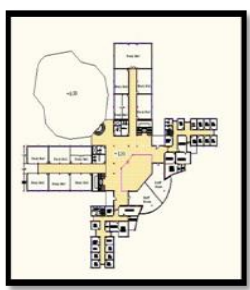

شكل (V): مخطط الطابق المرجع: مديرية الهندسة

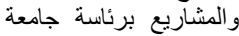

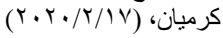

ــــ الزيارات المبي/نبة والملاحظات الشخصبة لعبنة الدراسة (مبنى كلية العلوم (9) قصم العندسة المدنية)

• يوجد (sky light) في أعلى سقف المبنى ومطل على المدخل بدون أية فتحة لتهوية المبنى و التبريد اليلي

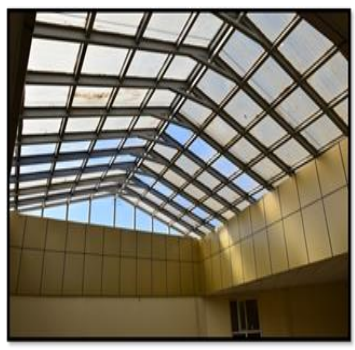

شكل (1) - (1): سقق بهو الكلية

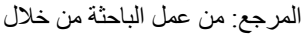
الزيارات الميدانية لموقع الدراسة.

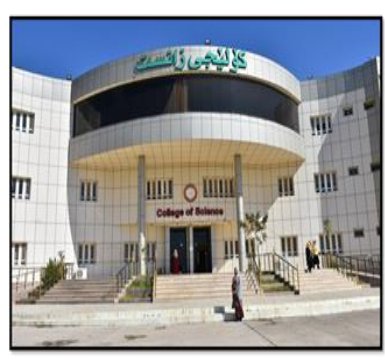

شكل (• ( ): المبنى من الخارج

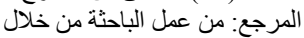
الزيارات الميدانية لموقع الدراسة.

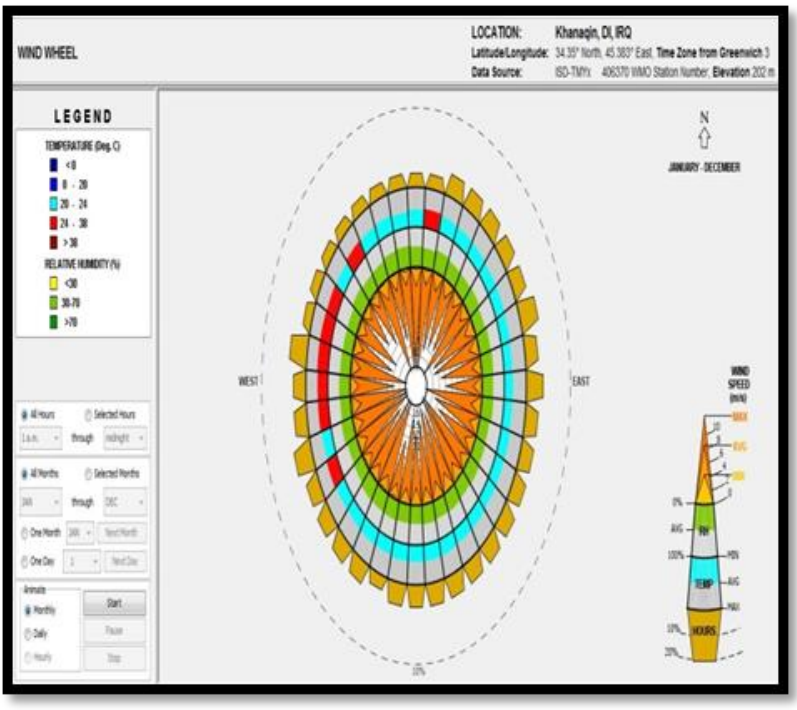

شكل (乏) : وردة الرياح خلال السنة في منطقة الدراسة

المرجع: من عمل الباحثة بإستخدام برنامج (Climate Consultant)

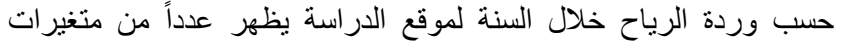

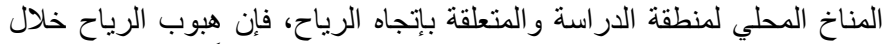

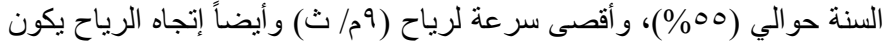

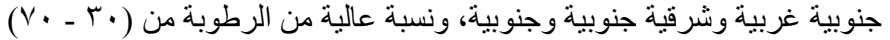

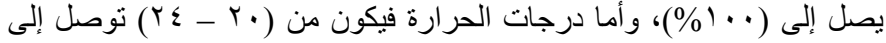

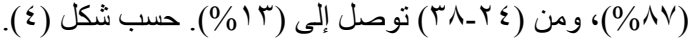
r ـ ـ ـ : إستر/تيجيات التصميم لموقع الدر/سة خلال السنة

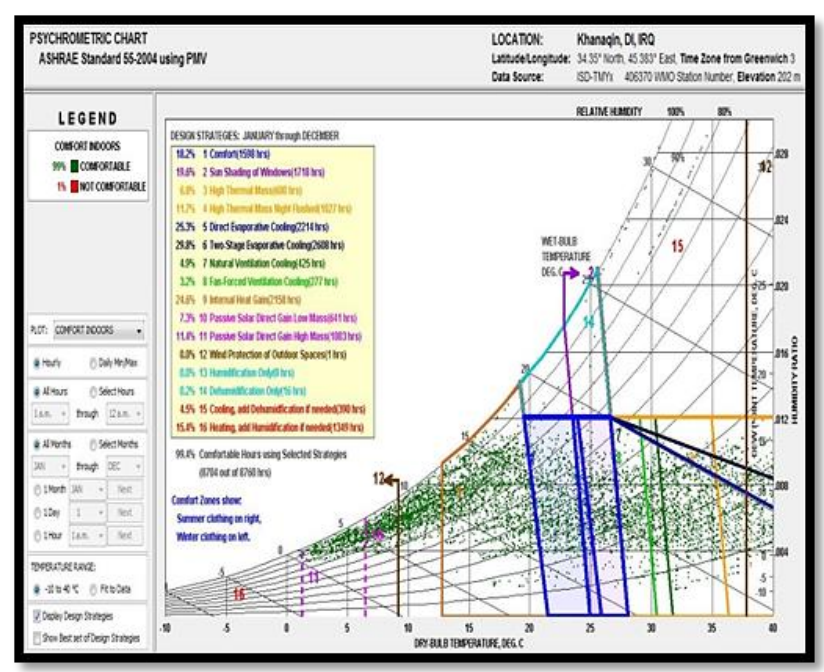

شكل (0): استر اتيجيات التصميم خلال السنة في منطقة الدراسة

المرجع: من عمل الباحثة بإستخدام برنامج (Climate Consultant)

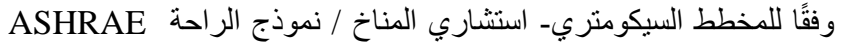
Standard 55

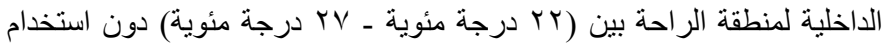
استر اتيجيات سلبية أو نشطة للتبريد و التدفئة. 


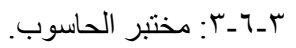

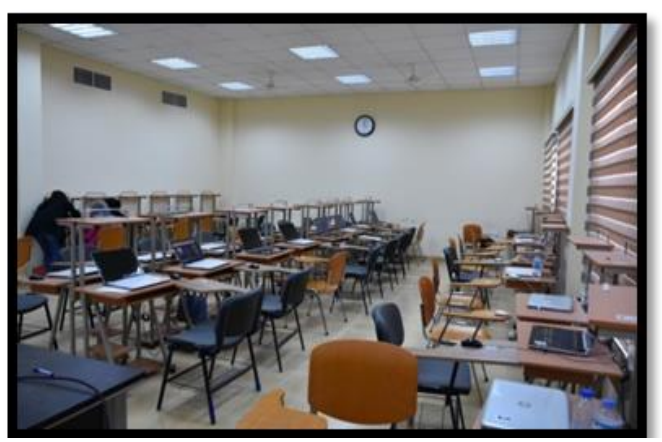

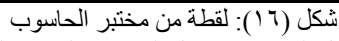

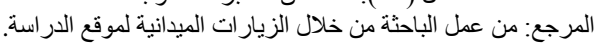

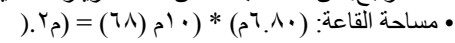

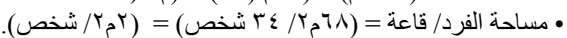

• • إرتفاع القاعة = (باعة القاعة).

مه إنسداد جميع النو افذ و إستخدام إنارة إصطناعية بسبب التو هج العالي للثمس

و عدم وجود كاسر ات شمسية على الثبابيك.

"ا ـ 7 : توصيف عبنة الدراسة: (الفراغات التعليمبة في جامعة كرمبان - مبنى كلية

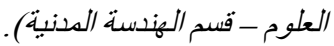

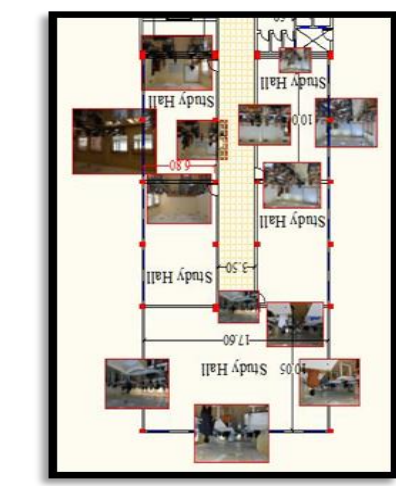

شكل (T (1) ): مخطط الفر اغات التعليمية_عينة الدراسة

المرجع: مديرية الهندسة و المشاريع برئاسة

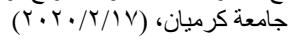

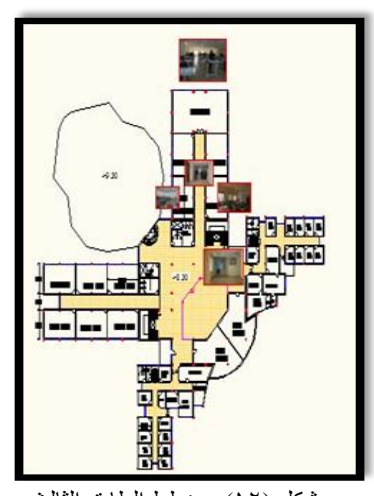

شكل (r ( ): مخطط الطابق الثالث

المرجع: مديرية الهندسة والمشاريع برئاسة

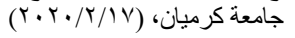

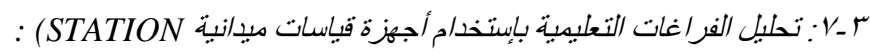
METEO ARADIOGUIDEE).

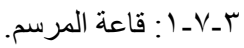

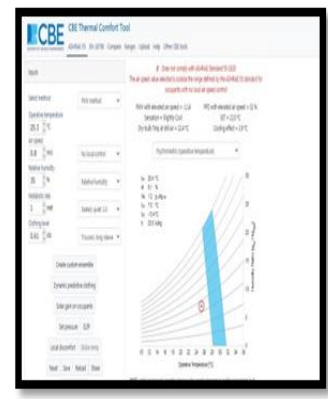

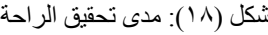
برإستخدام أجهزة قياسات ميدانية. المرجع: من عمل الباحثة بإستخدام برنامج(CBE Tool)

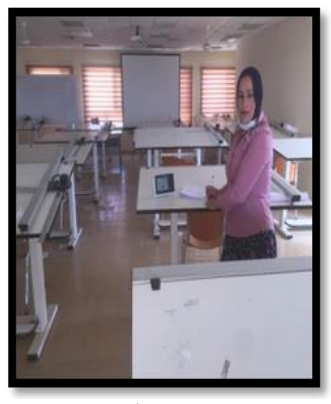

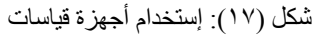
ميدانية في قاعة المرسم.

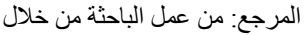
الزيارات الميدانية لموقع الدراسة.

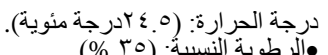

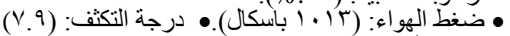

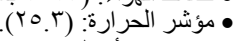

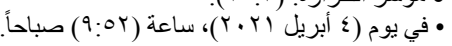
r r-V_r

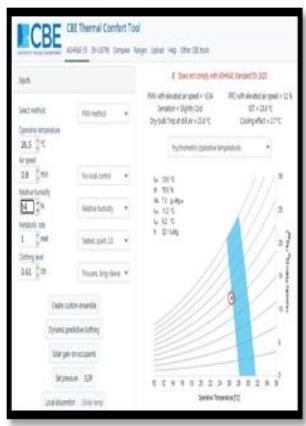

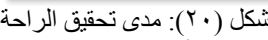
بإستخدام أجهزة قياسات ميدانية. المرجع: من عمل الباحثة بإستخدام برنامج (CBE Tool)

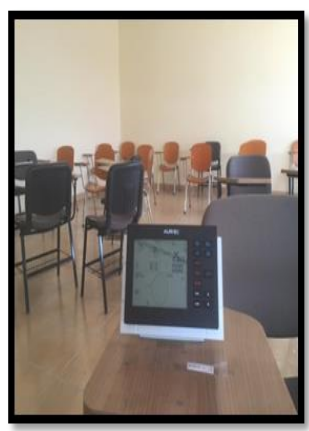

شكل (9 (19): إستخدام أجهزة قياسات ميدانية في القاعة الدر اسية.

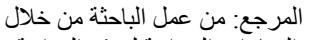
الزيارات الميدانية لموقع الدراسة.

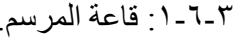

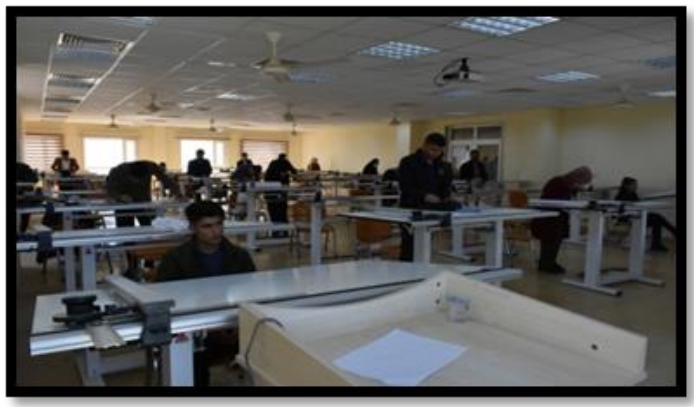

شكل (ع ا ): لقطة من قاعة المرسم

المرجع: من عمل الباحثة من خلال الزيارات الميدانية لموقع الدراسة.

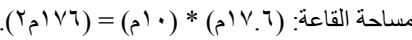

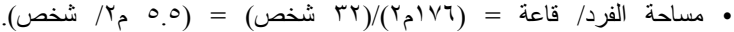
• • إرتفاع القاعة = ( (ّم). • إنجاه القاعة: الثرق و الثمال و الجنوب

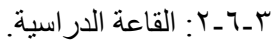

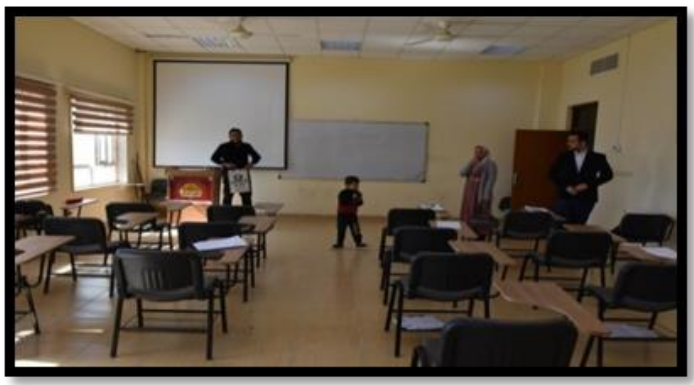

شكل (10): لقطة من القاعة الدراسية

المرجع: من عمل الباحثة من خلال الزيارات الميدانية لموقع الدراسة النة

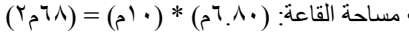

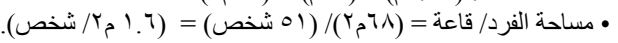

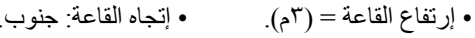




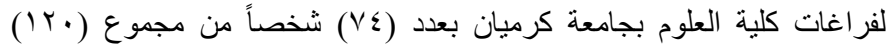

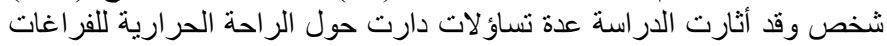

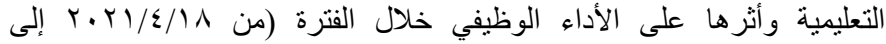
( $(r \cdot r) / 0 / 9$

ـ ـ ا : توصيف عينة الدر/سة الميد/نية:

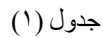
توصيف عبنة الدراسة الميدانية

\begin{tabular}{|c|c|c|c|c|}
\hline الدرجة & $\%$ & التكرارات & 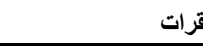 & \\
\hline الأول & 0. & re & ذكر & \multirow{2}{*}{ الجنس } \\
\hline الأول & 0. & $r v$ & أنثى & \\
\hline الأول & $V Y .9 V$ & $0 \leqslant$ & 11-11 سنة & \multirow{6}{*}{ الأعمار: } \\
\hline الثاني & 18.07 & $\pi$ & 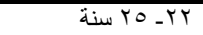 & \\
\hline الخامس & - & - & & \\
\hline الثالث & $\varepsilon .0$ & $r$ & . r r r سنة & \\
\hline 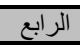 & Y.V. & $r$ & س & \\
\hline الرابع - الر ابع & r.v. & $r$ & أكثر من حr سنة & \\
\hline الثاني & $9 . \leqslant 7$ & V & هيئة تدريس & \multirow{2}{*}{ المهنة: } \\
\hline الأول & $9 . .0 \leqslant$ & TV & طالب & \\
\hline الأول & 07.10 & $\overline{\varepsilon Y}$ & كرميز مدن إدارة & \multirow{4}{*}{ مكان الإقامة: } \\
\hline الثاني & YI.TY & 17 & مركز مدن خارج & \\
\hline الثالث & $r \cdot Y V$ & 10 & الضواحي. & \\
\hline 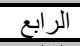 & $1 . r 0$ & 1 & الريف. & \\
\hline الثالث & $r 1 . \cdot 1$ & rr & أقل من (• (1) ساعات. & \multirow{3}{*}{ الفراغات خلإل الأسبو في } \\
\hline الثناني & $T Y . \varepsilon T$ & $\overline{r \varepsilon}$ & 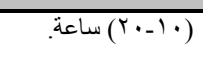 & \\
\hline الأول & $r ч . \varepsilon \lambda$ & $\overline{r V}$ & أكثر من (··) ساعة. & \\
\hline
\end{tabular}

s _ r : العوامل المؤثرة على الر/حة الحرارية داخل الفراغات التعليمية.

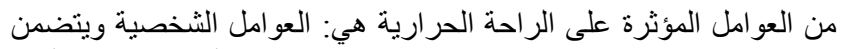

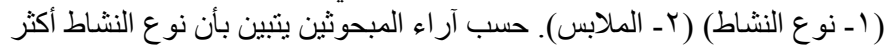

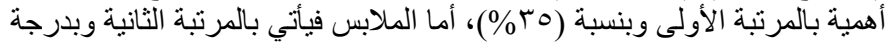

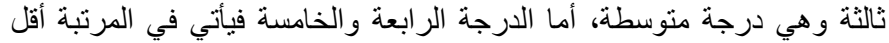

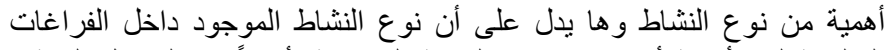

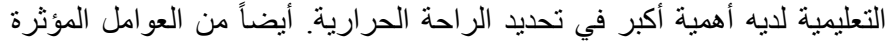

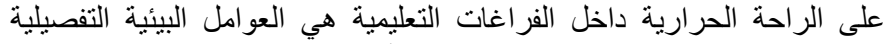

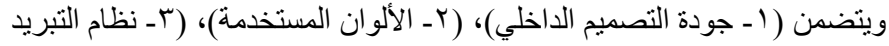

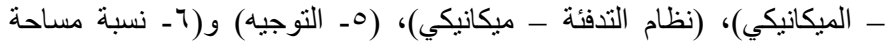

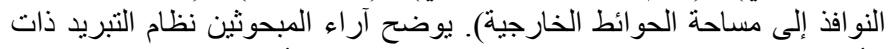

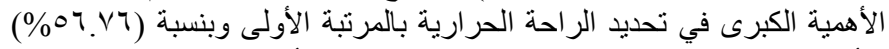

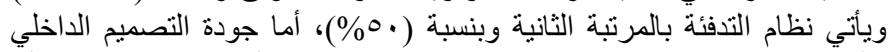

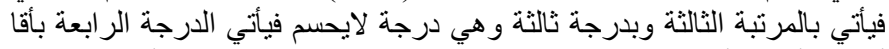

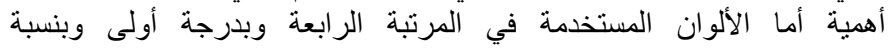

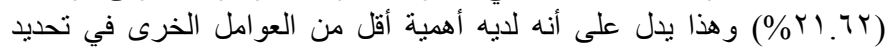

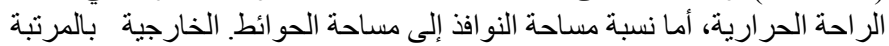

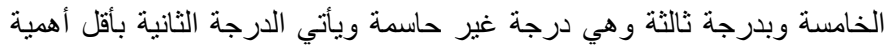

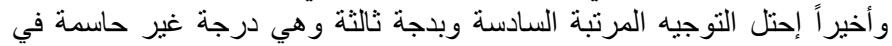
تحديد الراحة وهذا يدل على ضعف أهميته في تحديد الراحة الحرارية داخية داخل الفر اغات التعليمية

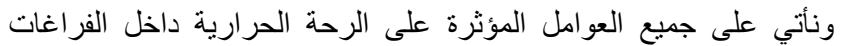

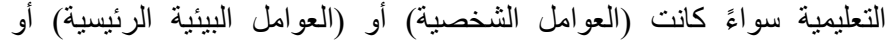

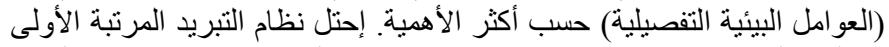

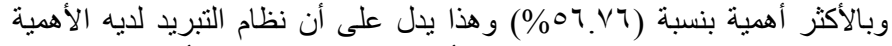

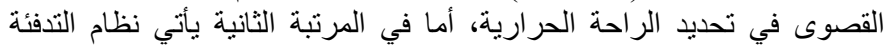

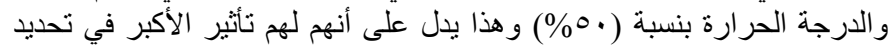

(مرجة الجرارة: (0.0 ك كدرجة مئوية).

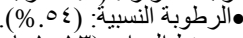

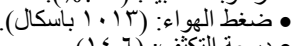

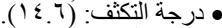

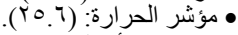

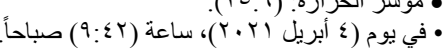

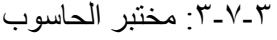

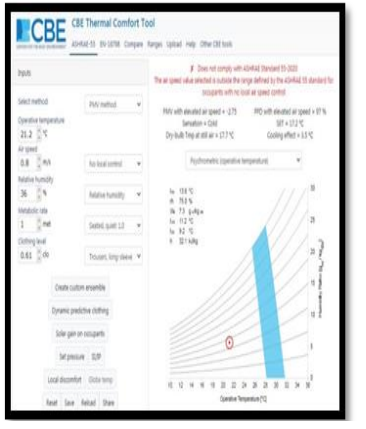

شكل (Yr): مدى تحقيق الراحة بإستخدام أجهزة قياسات ميدانية.

المرجع: من عمل الباحثة بإستخدام برنامج (CBE Tool)

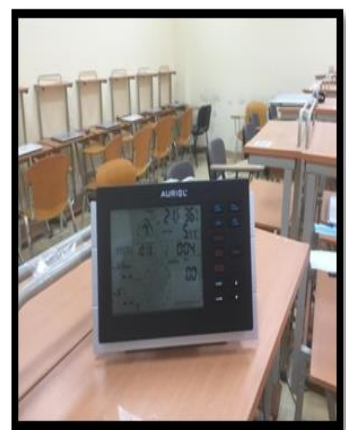

شكل (بآج): إستخدام أجززة قياسات

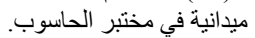

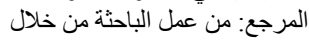
الزيارات الميدانية لموقع الدراسة.

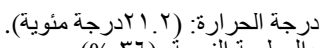

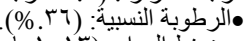

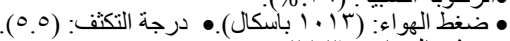

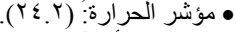

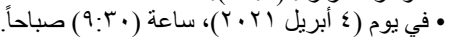

r-_-V_: إستخدام أجهزة قياسات ميدانية في خارج المبنى.

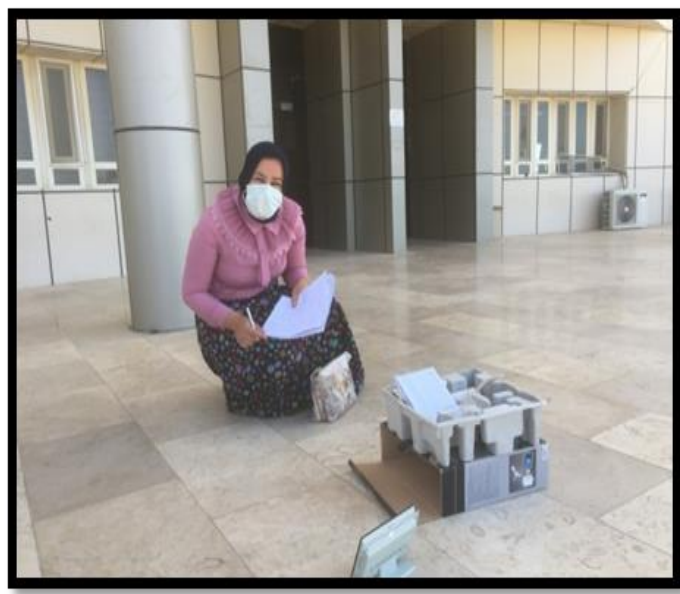

شكل (rT): إستخدام أجهزة قياسات ميدانية في خارج المبنى.

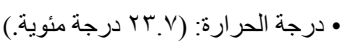

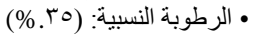

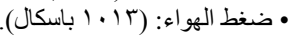

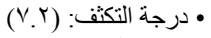

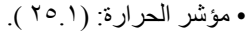

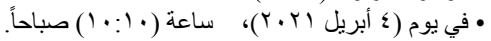

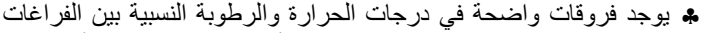

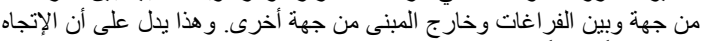

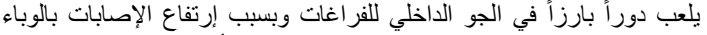
لايوجد طلاب داخل ألكلية في الوقت الذي نم إستخدام الأجهزة.

\section{ع. الدر اسة الميدانية}

يتركز هذه الدراسة للتعرف على "الر احة الحرارية للفر اغات التعليمية و أثرها على الأداء الوظيفي"، وذلك بمسح عينة من المدرسين والطلاب الطرابل الثاغلين 


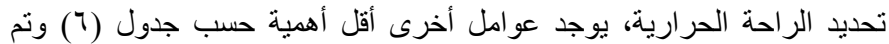

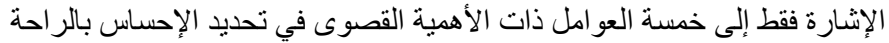

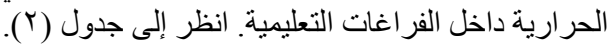

الراحة الحرارية داخل افراغات التعليمية لأن (نظام التبريد والتدفئة) نحتاجهم

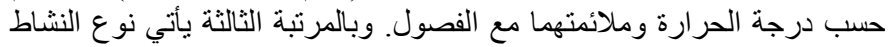

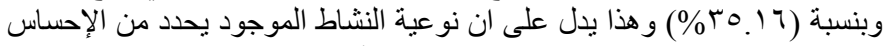

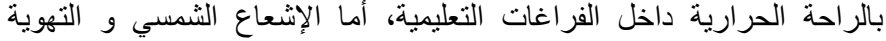

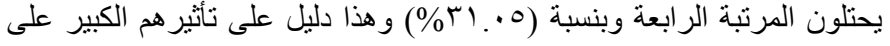

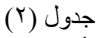

العو امل المؤثرة على الر احة الحرارية داخل الفر اغات التعليمية لاى أعضاء هيئة التدريس و الطلاب الثاغلين لفر اغات كلية العلوم بجامعة كرميان.

\begin{tabular}{|c|c|c|c|c|c|c|c|c|c|c|c|}
\hline \multicolumn{2}{|c|}{ ○ } & \multicolumn{2}{|c|}{$\varepsilon$} & \multicolumn{2}{|c|}{ r } & \multicolumn{2}{|c|}{ r } & \multicolumn{2}{|c|}{1} & \multirow{2}{*}{\multicolumn{2}{|c|}{ الفقرات }} \\
\hline$\%$ & s & $\%$ & ك & $\%$ & ك & $\%$ & ك & $\%$ & ك & & \\
\hline$r 0.17$ & rY & $Y \leqslant, Y Y$ & 11 & YQ.VY & YY & 7.10 & 0 & $\varepsilon 0$ & $r$ & نو ع النشاط. & العو امل \\
\hline$r \cdot r q$ & 10 & $T \leqslant . Y T$ & 11 & $r 7 . \leqslant 1$ & TV & $1 Y .17$ & 9 & 7.10 & 0 & الملابس. & الشخصية \\
\hline 0. & re & $1 \cdot . r \Lambda$ & $\wedge$ & $1 \leqslant .17$ & 11 & 7.10 & 0 & $1 V .07$ & 14 & درجة الحرارة. & \\
\hline ri..o & rT & $17 . r 4$ & IT & TI.TY & 17 & $1 \leqslant . \wedge 7$ & 11 & 17.51 & IT & الإشعاع الثمسي. & العوامل البيئية \\
\hline 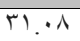 & KT & rY.qV & IV & $r 1 . \wedge$ & rT & $0 . \Sigma T$ & $\varepsilon$ & $9 . \leqslant 0$ & V & التهوية. & \\
\hline IV.OV & 14 & $1 \leqslant . \wedge T$ & 11 & $r \varepsilon . T r$ & 11 & TI.Tr & 17 & TI.TY & 17 & الرطوبة النسبية. & \\
\hline$r \cdot T V$ & 10 & YI.TY & 17 & $r V . \cdot \varepsilon$ & $r \cdot$ & 11.91 & $1 \varepsilon$ & 14.17 & 9 & جودة التصميم الداخلي. & \\
\hline $17 . r 5$ & IY & 15.01 & 1. & rT.YA & ro & 15.01 & 1. & KY.qY & IV & الألوان المستخدمة. & \\
\hline $07 . \mathrm{VA}$ & $\varepsilon r$ & 15.01 & 1. & 15.01 & 1. & $1 \cdot r \Lambda$ & $\wedge$ & $0 . \sum Y$ & $\varepsilon$ & نظام التبريد (ميكانيكي). & التوامل البينية \\
\hline 0. & re & Ir.IV & 9 & $1 . r 9$ & $\wedge$ & $1 \leq . \wedge V$ & 11 & IT.IV & 9 & نظام التذفئة (مبكانيكي). & \\
\hline $9 . \leqslant 0$ & V & $17.1 Y$ & IT & r4.7. & YV & 17.41 & Ir & YI.TY & 17 & التوجيه. & \\
\hline $1 . . \lambda r$ & $\wedge$ & $r \cdot . r V$ & 10 & $r q . V Y$ & rr & ro.TV & 19 & 15.01 & 1. & نساحة مساحة النو الفذ إلى . & \\
\hline
\end{tabular}

أما المرتبة الرابعة وبدرجة أولى التوجيه من حيث التهوية وجودة التصميم التوبيم

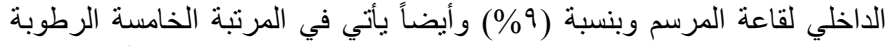

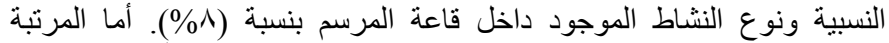

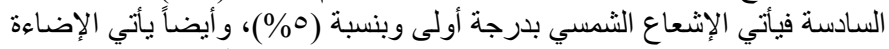

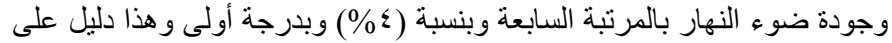

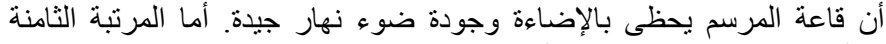
و الأخيرة وهي الملابس بدرجة أولى وبنسبة (؟\%\%). انظر إلى جدول (؟ّ).
ـ ـ"r. مستوى الراحة الحرارية داخل الفراغات التعليمية.

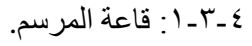

حسب آراء المبحوثين فإنهم إختاروا بالمرتبة الأولى وبالنسبة (10 (10) نظام التبريد و هذا يدل على أن قاعة المرسم يحتاج إلى تحسين نظام التبن التبريد. أيضاً يأتي

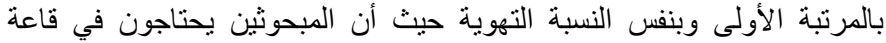

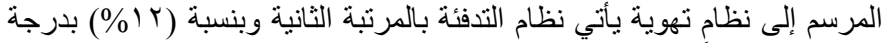
أولى ويأتي أيضاً درجة الحرارة بالمرتبة الثالثة وبدرجة أولى وبنسبة ولنية (1) (1\%).

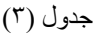

آراء أعضاء هيئة التدريس والطلاب الثشاغلين للفر اغات التعليمية بمبنى كلية العلوم بجامعة كرميان حول مستوى تحقيق الراحة الحرارية داخل قاعة المرسم.

\begin{tabular}{|c|c|c|c|c|c|c|c|c|c|c|c|}
\hline \multicolumn{2}{|l|}{ 0 } & \multicolumn{2}{|c|}{ ๕ } & \multicolumn{2}{|c|}{$r$} & \multicolumn{2}{|c|}{ r } & \multicolumn{2}{|c|}{1} & \multirow{2}{*}{\multicolumn{2}{|c|}{ رأي أعضاء هيئة التّريس والطلاب حول مدى تحقيق عوامل الراحة الحرارية في قاعة }} \\
\hline$\%$ & s & $\%$ & ك & $\%$ & s & $\%$ & s & $\%$ & S & & \\
\hline $1 \wedge . r \varepsilon$ & 11 & $4 . .74$ & r r & rT.rT & $1 \varepsilon$ & $\Lambda . \Gamma \varepsilon$ & 0 & Tr. & $\wedge$ & لالدر القوةة الكافية لأداء أبي حركة في قاعة المرسم و أنشعر معها بالر احة & 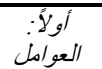 \\
\hline ro & r) & Y7.TV & 17 & tr.tr & $1 \varepsilon$ & 1. & 7 & 0 & r & سأرندي ملابس مختلفة حسب الموسم ودرجة الحر ارة، وساتَمتع بر احة & الشخصية \\
\hline $1 \Lambda . r \varepsilon$ & 11 & Ther & $\Lambda$ & $r 1.7 \mathrm{~V}$ & 19 & $\overline{11 . .4 \mu}$ & 11 & $\overline{1 \Lambda . r Y}$ & 11 & درجة الحرارة العادية في المرسم تجعلني أشعر أنني بحالة جيدة. & ثانياً. \\
\hline ro & 10 & YI.74 & ir & 4.77 & IT & זrt & $1 \varepsilon$ & 1.T० & . & أنشعة الثمس الثد الدخل إلى قاعة المرسم بشكل طبيعي و لا أنز عج منها حتى & العوامل \\
\hline 10 & q & 10 & 9 & $r 1.7 \mathrm{~V}$ & $1 T$ & rt.rt & $1 \leqslant$ & ro & 10 & لاحظت أن التهوية في المرسم كانت طبيعية وشعرت معها بالر احة. & الرئيسية. \\
\hline$r 1.74$ & Tr & ro & 10 & ro & 10 & 10 & 9 & $1 \Gamma . \Gamma \varepsilon$ & $\Lambda$ & بساعد مستوى الرطوبة المتو ازن على التركيز. & \\
\hline Tr.r & $\Lambda$ & 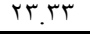 & $1 \leq$ & r. & 11 & $1 \wedge . r \varepsilon$ & 11 & 10 & 9 & تصميم قاعة المرسم هندسي ومنتظم. & \\
\hline rt.rt & $1 \varepsilon$ & TI.TV & 19 & Tr.TY & $1 \varepsilon$ & $\Lambda . \Gamma \varepsilon$ & $\circ$ & $1 T . K r$ & $\Lambda$ & تساعد الألوان المستخدمة في قاعة المرسم على جودة الإضـاءة الطبيعية. & \\
\hline $17.7 \mathrm{~V}$ & 1 . & retre & $1 \leqslant$ & r. & ir & 10 & 9 & ro & 10 & 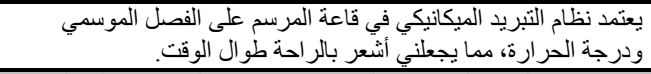 & \\
\hline 17.77 & 1 . & Y7.7V & 17 & Tr.TT & $1 \varepsilon$ & IT.re & $\wedge$ & r. & ir & 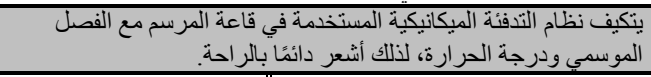 & إثاًاً: \\
\hline $17.7 \mathrm{~V}$ & $1 \cdot$ & ro & 10 & $r 1.77$ & 14 & $r 1.7 \mathrm{~V}$ & 14 & 10 & 9 & 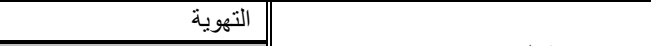 & الئl البئية \\
\hline ro & 10 & $r \wedge . T \leq$ & rr & rt.rs & $1 \varepsilon$ & 7.77 & $\varepsilon$ & 7.77 & $\varepsilon$ & 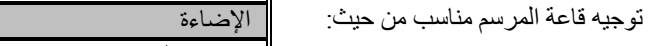 & التنصبية \\
\hline $\mid \Lambda, r \varepsilon$ & 11 & ro & YI & $r 7.77$ & 17 & 11.77 & V & $\lambda . r \varepsilon$ & 0 & الإشعاع الثمسي & . \\
\hline r..77 & rr & r. & 11 & $1 \Lambda . r \varepsilon$ & 11 & $\Lambda . \Gamma \varepsilon$ & ० & 7.77 & $\varepsilon$ & يساعد على تحقيق جودة النو ضو الحو النط الخارجية في قاعة المرسم وتوزيعها & \\
\hline
\end{tabular}


الرابعة وبدرجة أولى يأتي الإضاءة و الألوان المستخدمة أما في المرتبة الخامسة

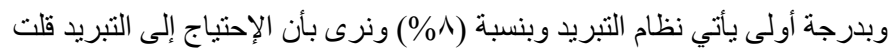

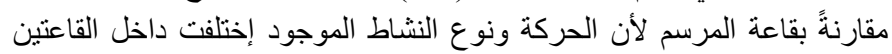

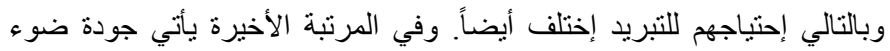

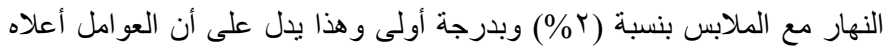

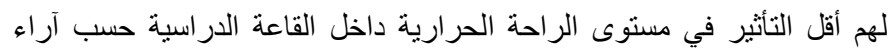

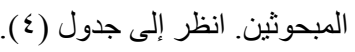

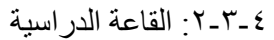

نلاحظ المبحوثين يعانون من مشاكل جودة التصميم الداخلي في القاعة

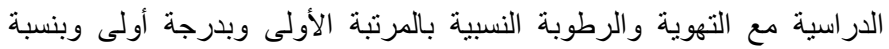

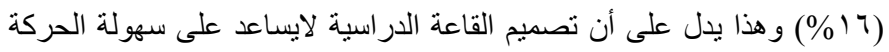

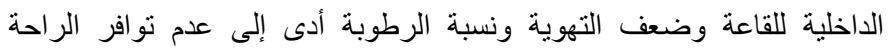

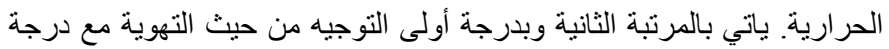

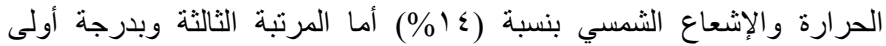

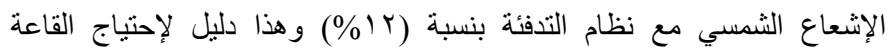

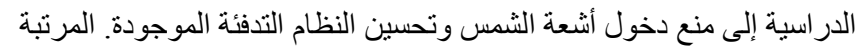

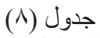

آراء أعضاء هيئة التدريس و الطلاب الثاغلين للفر اغات التعليمية بمبنى كلية العلوم بجامعة كرميان حول مستوى تحقيق الراحة الحر ارية داخل القاعة الدراسية.

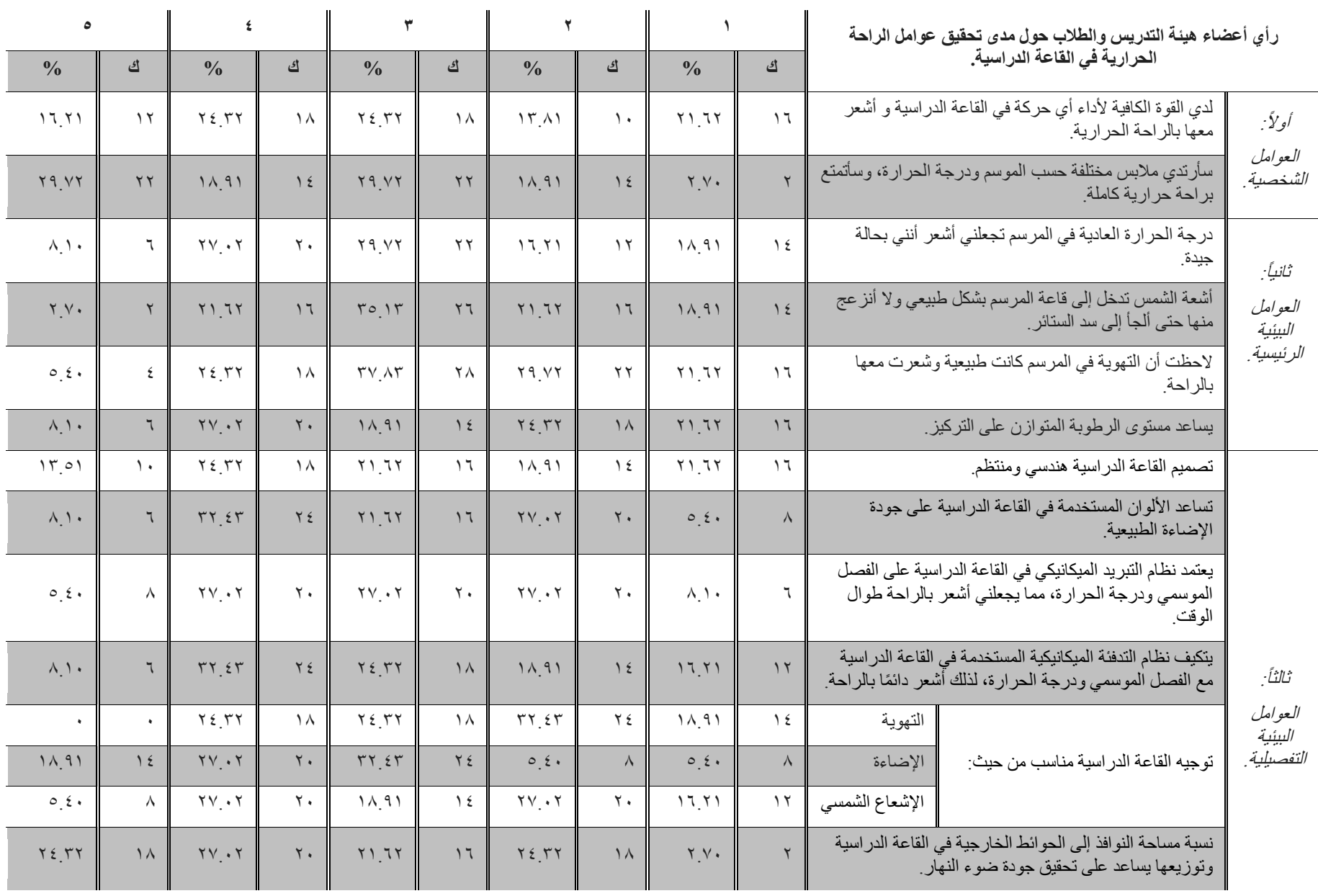

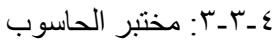

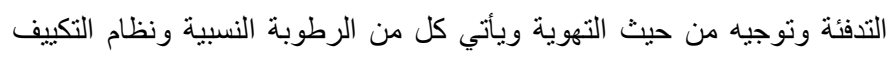

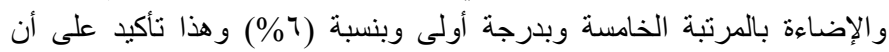

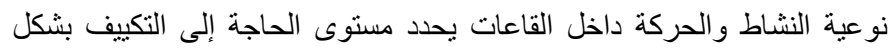

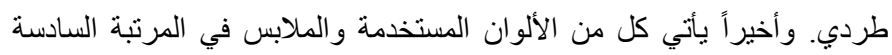
وبدرجة أولى وبنسبة (ع\%). انظر إلى جدول (0).

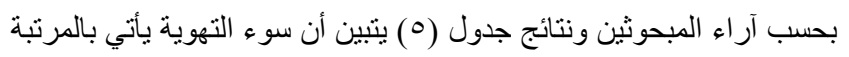

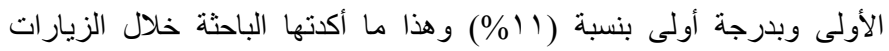

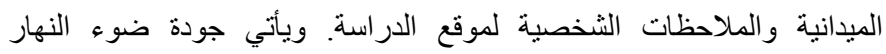

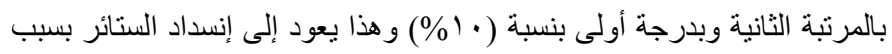

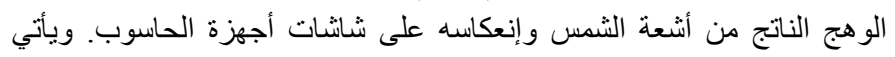

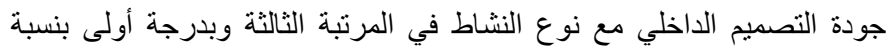

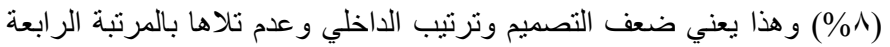
وبدرجة أولى وبنسبة (†\%) كل من درجة الحرارة و الإشعاع الثمسي ونظام 


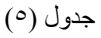

آراء أعضاء هيئة التدريس و الطلاب الثاغلين للفر اغات التعليمية بمبنى كلية العلوم حول مسنوى تحقيق الر احة الحرارية داخل قاعة الحاسوب.

\begin{tabular}{|c|c|c|c|c|c|c|c|c|c|}
\hline \multicolumn{2}{|c|}{0} & \multicolumn{2}{|c|}{ z } & \multicolumn{2}{|c|}{$r$} & \multicolumn{2}{|c|}{$r$} & \multicolumn{2}{|c|}{1} \\
\hline$\%$ & ك & $\%$ & (5) & $\%$ & 5 & $\%$ & 5 & $\%$ & 5 \\
\hline $1 \varepsilon$ & V & דז & 11 & $r \leq$ & Ir & 11 & 9 & 17 & $\wedge$ \\
\hline Tr & 17 & דr & 11 & $r$. & 1. & $\varepsilon$ & r & $\wedge$ & $\varepsilon$ \\
\hline 11 & 9 & $r \leqslant$ & IT & YT & $1 \pi$ & 11 & 9 & $1 \varepsilon$ & V \\
\hline דו & ז & Yr & 11 & 11 & $q$ & r. & 1. & $1 \leqslant$ & $v$ \\
\hline $1 \leqslant$ & V & YA & $1 \varepsilon$ & $r$. & 1. & 17 & $\wedge$ & $r Y$ & 11 \\
\hline IT & 7 & KY & $\pi$ & $r$. & 10 & $r$. & 1. & IT & 7 \\
\hline Ir & 7 & rᄉ & 19 & $Y Y$ & 11 & IY & 7 & 17 & $\Lambda$ \\
\hline 11 & 9 & $r \varepsilon$ & Ir & Tr & 11 & YA & $1 \leqslant$ & $\wedge$ & $\varepsilon$ \\
\hline Ir & 7 & ץ & 19 & $r T$ & 11 & 17 & $\wedge$ & Ir & 1 \\
\hline $1 \leqslant$ & V & 11 & $q$ & Y & $1 \leqslant$ & דו & $1 \pi$ & $1 \leqslant$ & V \\
\hline 1. & 0 & Y & $\pi$ & 4 & 11 & $1 \varepsilon$ & V & $1 \varepsilon$ & V \\
\hline $1 \leqslant$ & V & $r$. & 10 & YT & $1 \pi$ & 11 & 9 & IT & 7 \\
\hline$r$. & 1. & $T \leq$ & 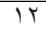 & $r_{\Lambda}$ & $1 \varepsilon$ & $1 \leqslant$ & V & $1 \leqslant$ & V \\
\hline 17 & $\wedge$ & $r \varepsilon$ & Ir & $r \varepsilon$ & IT & 17 & $\wedge$ & $r$. & 1. \\
\hline
\end{tabular}

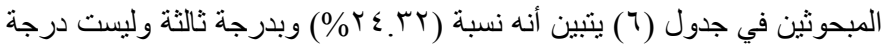

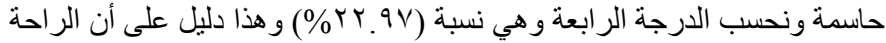

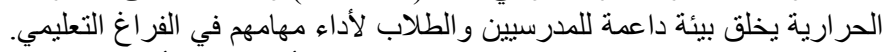

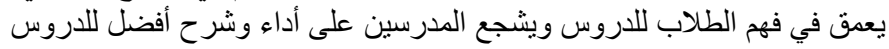

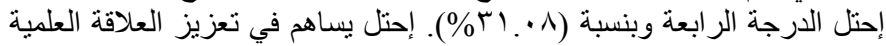

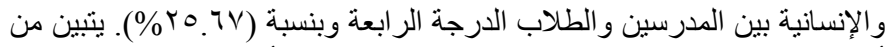

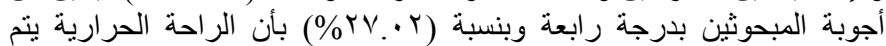

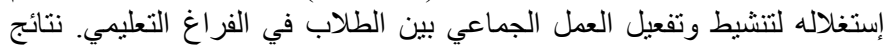

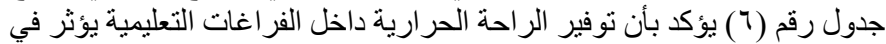

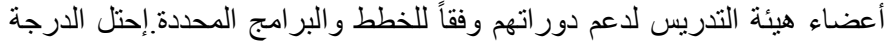

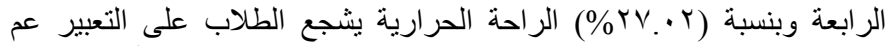

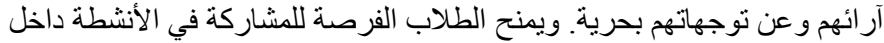

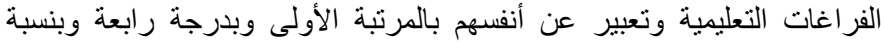

( ( rq.Vr)
رأي أعضاء هيئة التّريس والطلاب حول مدى تحقيق عوامل الراحة الحرارية في قاعة الحاسوب. لادي القوة الكافية لأداء أي حركة في قاعة الحاسوب وأشعر معها بالراحة

العوامل الثخصية.

درجة الحر ارة العادية في قاعة الحاسوب تجعلنى أشعر أننى بحالة جيدة.

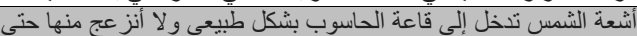

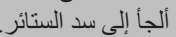

بالراحظت أن التهوية في قاعة الحاسوب كانت طبيعية وشعرت معها

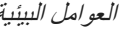

الرئبسية. يساعد مستوى الرطوبة المتو ازن على التركيز. تصميم قاعة الحاسوب هندسي ومنتظم.

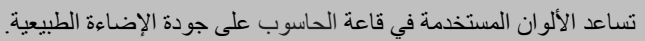

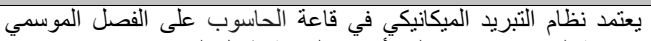

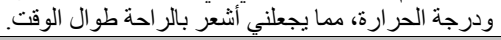

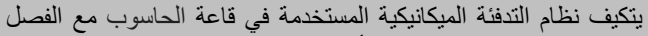
ألموسمي ودرجة الحرارة، لذلك أشعر دائمًا بالتراحة. ثاثاً: العوامل البيئية التفنيلية.
ـ ــ : أثر الراحة الحرارية على الأداء الوظبفي داخل الفراغات التعليمية.

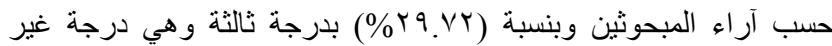

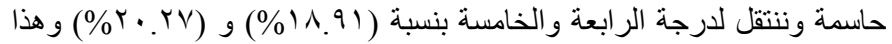

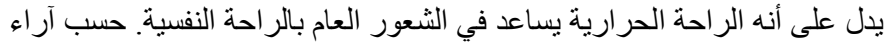

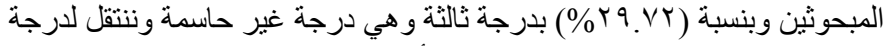

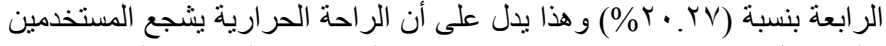

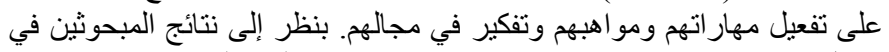

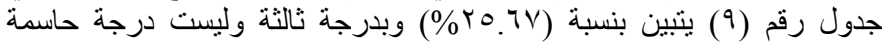

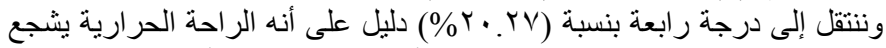

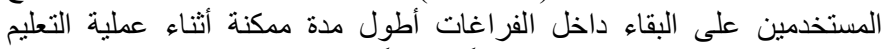

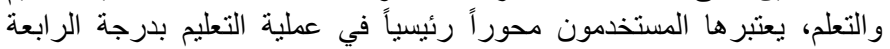

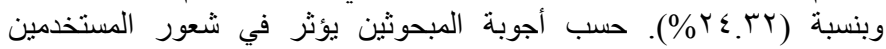

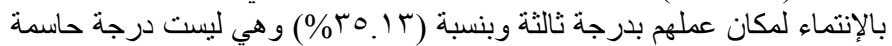

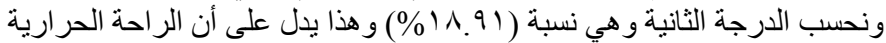
لايؤثر في شعور الستخدمين بالإنتماء لمكان عملهم. بانظر إلى نتائج أجوبة النة

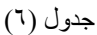

آراء أعضاء هيئة التنريس والطلاب لقسم الهندة الددنية حول أثر الراحة الحرارية على الأداء الوظيفي.

\begin{tabular}{|c|c|c|c|c|c|c|c|c|c|c|}
\hline \multicolumn{2}{|c|}{0} & \multicolumn{2}{|c|}{ \& } & \multicolumn{2}{|l|}{$r$} & \multicolumn{2}{|l|}{ r } & \multicolumn{2}{|l|}{1} & روية أعضاء هيئة التدريس والطلاب حول أثر الراحة الحرارية على الأداء الوظيفي \\
\hline$\%$ & ك & $\%$ & s & $\%$ & ك & $\%$ & ك & $\%$ & ك & \\
\hline$Y \cdot, Y Y$ & 10 & 11.91 & $1 \varepsilon$ & YQ.VY & TY & $17 . \mathrm{Y1}$ & IT & $1 \leqslant . \wedge 4$ & 11 & ببساعد في الشعور العام بالر/حة النفسية. \\
\hline 14.17 & 9 & rY.qY & IV & YQ.VY & Kr & $1 \% .04$ & 15 & 17.41 & Ir & يشجع الدستخدمين على تفعيل مهار/تهم وموا هبهر والتفكير في مجالهم. \\
\hline $1 \cdot . \wedge 1$ & $\Lambda$ & $r \cdot T_{V}$ & 10 & ro.TV & 19 & $17 . \mathrm{Y}$ & Tr & ro.TV & 19 & والتعجع. المستخدمين على البقاء داخل الفراغات أطول مدة مدكنة أثناء عملية التعليم \\
\hline $1 \mathrm{~V} .07$ & IT & TE.TY & 11 & YY.QY & IV & YI.TY & 17 & 15.17 & 9 & يتنبر ها المستخدمون محور أ رئبياً في عملية التعليم. \\
\hline $1 V .07$ & $\pi$ & 17.51 & IT & ro.1r & YY & 11.91 & $1 \varepsilon$ & 15.17 & 9 & يؤثر في شعور المستخذمبن بالإنتحاء لمكان عمهر. \\
\hline 11.91 & $1 \varepsilon$ & rY.9V & IV & TE.TY & 11 & TI.TY & 17 & 15.17 & 9 & يخلق بيئة داعمة للمدرسين والطلاب لوداء مهامهج في الفراغ التعلبيمي. \\
\hline$r \cdot T^{T V}$ & 10 & $T \cdot Y V$ & 10 & 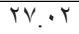 & r. & rY.QY & IV & 17.41 & Ir & ببساعد الددرسين والطلاب في التركيز د/خل الفراغ التعليهي أثناء أداء الدروس. \\
\hline $9 . \varepsilon_{0}$ & V & $r 1 . \cdot 1$ & re & To.TV & 19 & TE.TY & 11 & $9 . \leqslant 0$ & $\mathrm{~V}$ & للدروس في فهم الطلاب للاروس ويشجع العدرسين على أداء و شرح أفضل \\
\hline 17.15 & IT & ro.TV & 19 & TY.QY & IV & $1 \% .07$ & $1 \pi$ & $1 \% .07$ & $1 \pi$ & بباهم في تعزيز العلاقة العلدية و الإنسانية بين المدرسين والطلاب. \\
\hline $1 \mathrm{~V} .07$ & $1 \pi$ & To.TV & 19 & TE.TY & 11 & 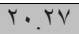 & 10 & $1 \cdot . \wedge 1$ & $\Lambda$ & يتيح فرصاً أكثر ملائمة لاداء الدورس العملية باكماها. \\
\hline$Y \cdot, Y Y$ & 10 & TY. & r. & rT.9V & IV & $1 \% .07$ & $1 \pi$ & 14.17 & 9 & يتم إستغلاله لتنشيط وتفعيل العمل الجماعي بين الطلاب في الفراغ التعليبي. \\
\hline rr.qY & IV & KQ.Vर & TY & 15.17 & 9 & $r \varepsilon . \cdot \varepsilon$ & 17 & $T \cdot . T V$ & 1. & 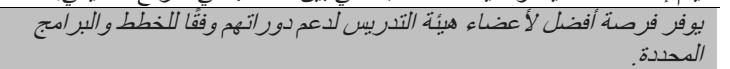 \\
\hline $1 \% .07$ & $\pi$ & 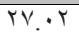 & $r \cdot$ & $r \varepsilon . \cdot \varepsilon$ & 17 & 11.91 & $1 \varepsilon$ & $0 . \varepsilon$. & $\varepsilon$ & يشجع الطلاب على التعبيير عن أرائهم والتعبير عن توجهاتهم بحرية. \\
\hline rY.qY & IV & YQ.VY & YY & 11.91 & $1 \varepsilon$ & $1 \% .07$ & $1 \pi$ & $9 . \leqslant 0$ & V & بينح الطلاب الفرصة للمشاركة في الأثشطة داخل الفراغ والتعبير عن أنفسهر \\
\hline
\end{tabular}




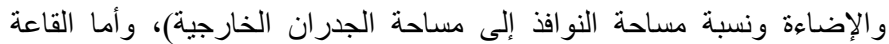

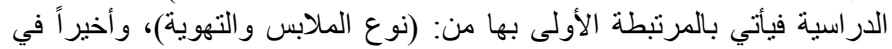

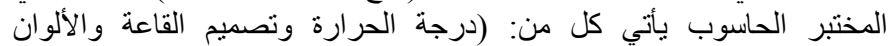

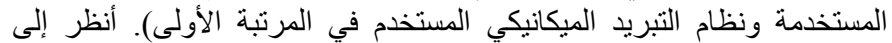

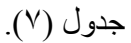

ــــ: مقارنة بين الفراغات التعليمية عبنة الدراسة عن طريق الدتوسطات الحسابية.

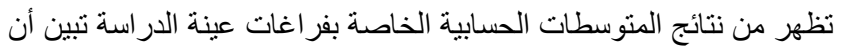

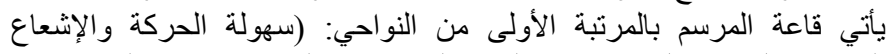
الثمسي والرطوبة النسبية ونظام التدفئة الميكانيكية والتوجة من حيث التهوية

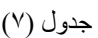

المتوسطات الحسابية الخاصة بالفر اغات التعليمية عينة الدراسة الميدانية

\begin{tabular}{|c|c|c|c|c|}
\hline 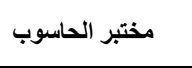 & القاعة الدراسية & 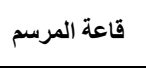 & \multicolumn{2}{|l|}{ المتوسط الحسابي حول مدى تحقيق عوامل الراحة الحرارية في الفراغات التعليمية } \\
\hline r.10 & r.YA & r.to & لدي القوة الكافية لأداء أي حركة وأشعر معها بالر احة الحر ارية. & 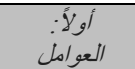 \\
\hline$r . \wedge$ & $r .01$ & r.ro & سأرتدي ملابس مختلفة حسب الموسم ودرجة الحرارة، وسأتمتع بر احة حر ارية كاملة. & الشخصية. \\
\hline$r .1 \varepsilon$ & r.A & r.9r & درجة الحر ارة العادية تجعلني أشعر أنني بحالة جيدة. & \\
\hline r.ru & r.74 & $r .19$ & أشعة الثمس تدخل بشكل طبيعي و لا أنز عج منها حتى ألجأ إلى سد الستائر. & العوامل البيينية \\
\hline$r .97$ & r.IV & $r . v i$ & لاحظت أن التهوية كانت طبيعية وشعرت معها بالر احذة. & \\
\hline$r .4$ & r.VT & r.Y & يساعد مستوى الرطوبة المتو ازن على التركيز. & \\
\hline$r .11$ & r.AT & r.9६ & تصميم القاعات هندسي ومنتظم. & \\
\hline$r . \wedge 1$ & r.9Y & r.气 & تساعد الألوان المستخدمة على جودة الإضـاءة الطبيعية. & \\
\hline t.rt & r.৩A & r.११ & بالر احة طو ال التبريد الميكانيكي على الفصل الموسمي ودرجة الحرارة، مما يجعلني أشعر & \\
\hline r.qr & r. $9 \leq$ & $r . \varepsilon^{\prime}$ & أُشعبر دائًَا بالر التدفة الميكانيكية المستخدمة مع الفصل الموسمي ودرجة الحرارة، لذلك & العوامل البيئية \\
\hline$r . \varepsilon$ & r.01 & $r .0$ & توجيه القاعات مناسب & التفصيلية. \\
\hline$r .17$ & r.Is & r.TV & من حيث: & \\
\hline$\varepsilon . \varepsilon \wedge$ & Y.71 & $r .01$ & الإشعاع الثمسي & \\
\hline$\varepsilon \varepsilon, r$ & $r . \leqslant r$ & T.VV & النهبة مساحة النوافذ إلى الحوانط الخارجية وتوزيعها يساعد على تحقيق جودة ضوء & \\
\hline
\end{tabular}

7. مقترحات وتوصيات الدراسة.

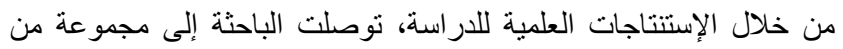

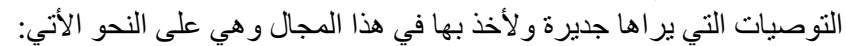

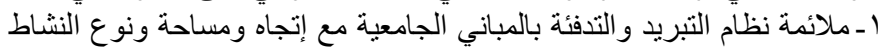

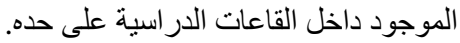
זـ ضرورة الإهتمام بالتهوية داخل المباني التعليمية سو اءء كانت التهوية طبيعية أو

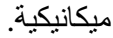

كـ ــ عمل كاسر ات شمسية على الثبابيك لتقليل التو هج.

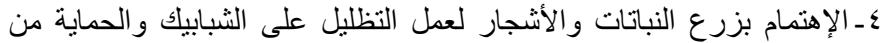
الأتربة و الجر اثيم ولصد الهو اء الغير محبب حسب إتجاه الرياح.

\section{AUTHORS CONTRIBUTION}

\section{Author 1 did the following:}

1- Research idea proposal .

2- Data collection and tools .

3- Data analysis and interpretation.

4- Investigation .

5- Methodology.

6- Software

\section{Author 2 and 3 did the following:}

1- Research idea development.

2- Methodology.

3- Permanent Supervision .

4- Drafting the article.

5- Final approval of the version to be published.

\section{هـ - نتائج الدراسة}

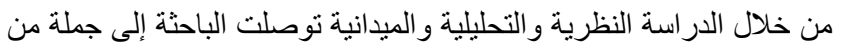

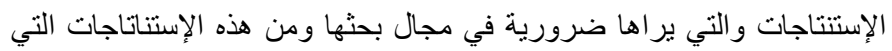

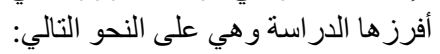

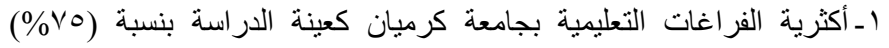

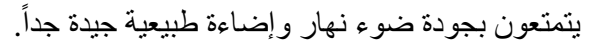

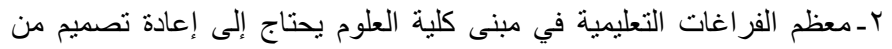

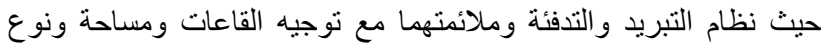

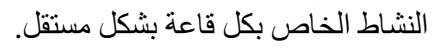

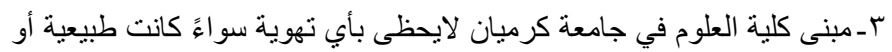

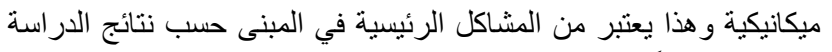

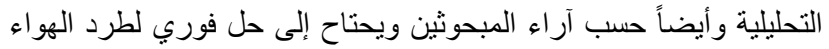

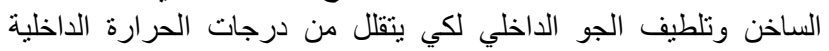
ويرتفع في مستوى تحقيق الر احة الحرارية وبالتالي تأثيره الكبير على الأداء الكاء الكاء

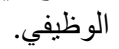
ـ ـ-حسب الدراسة التحليلية والزيارات الميدانية للموقع الدراسة تبينت إحتياج

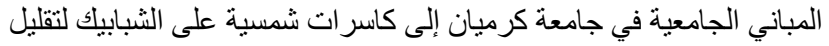

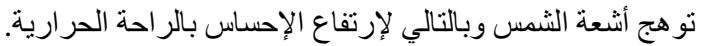

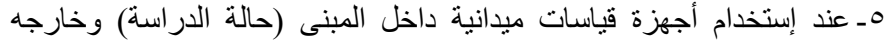

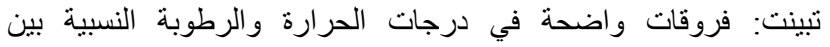

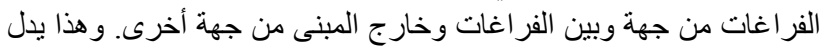
على أن الإتجاه يلعب دوراً بارزاً في الجو الداخلي للفر اغات. 
الحراري للمباني الجامعية (در اسة حالة) ودر اسة إمكانية إستبدال المو اد التقليدية

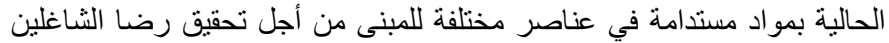

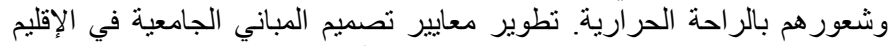

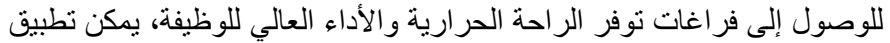

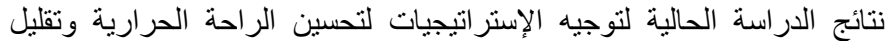
إستخدام الطاقة في المباني الجامعية، وكذلك لتصميم التهات مباني تعليمية جديدة.

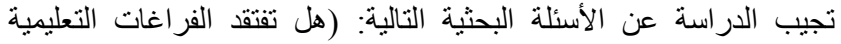

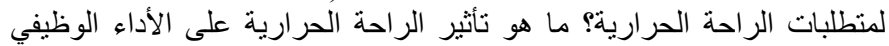

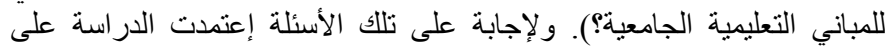

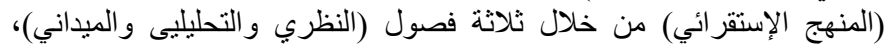

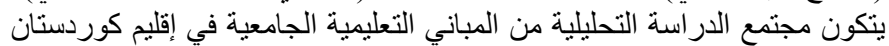

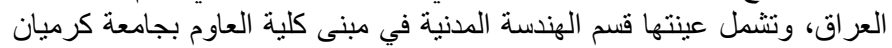

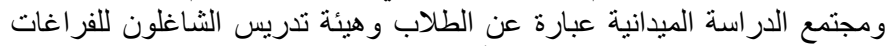

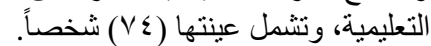

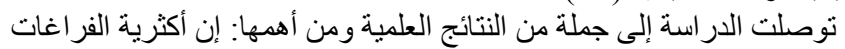

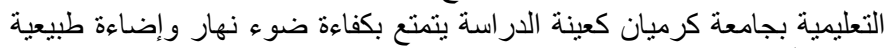

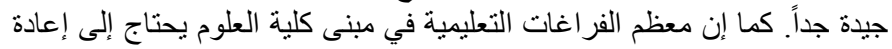

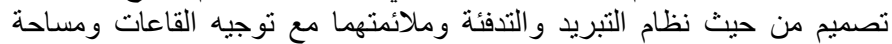

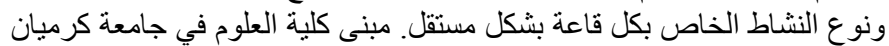

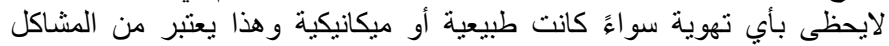

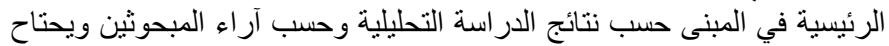

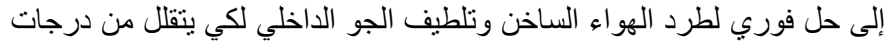

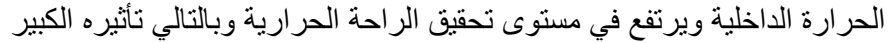

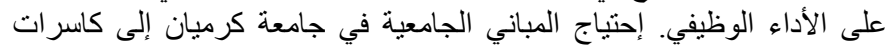

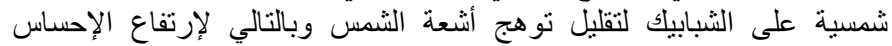

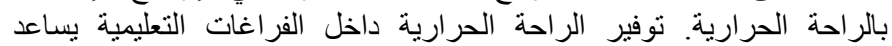

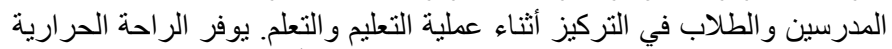

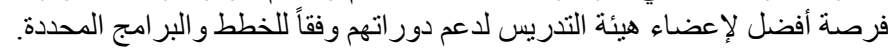

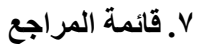

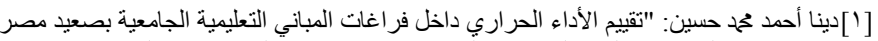

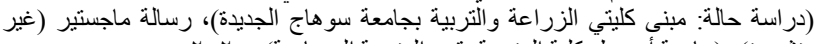

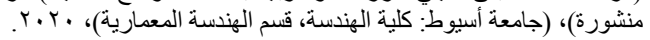

[2]Jin Dai and Shuguang Jiang: "Passive space design, building environment and thermal comfort: A university building under severe cold climate, China", Indoor and Built Environment Indoor and Built Environment, 2020, PP: 56-70.

[3] Gabriel Guevara, et al.: "Thermal comfort in university classrooms: An experimental study in the tropics", Building and Environment 187 (2021), PP: 1-21.

[4]Han Jiang, et al.:" Measuring students' thermal comfort and its impact on Learning", ERIC, International Conference on Educational Data Mining (EDM) (12th, Montreal, Canada, Jul 2-5, (2019), PP: 89-98.

[5]Thomas Sébastien, et al.: "Thermal comfort and air quality: One-year measurement, analysis and feed back to users of an educational building", Proceedings of $10^{\text {th }}$ Windsor Conference: Rethinking Comfort. (8 refs), (2018), PP: 1049-1061.

\section{Arabic title \\ (الر احة الحرارية للفر اغات التعليمبة بالمباني الجامعية وأثرها على

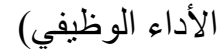 \\ در اسة حالة: جامعة كرميان بإقليم كوردستان العراق الت}

\section{Arabic abstract :}

هذه الدراسة بعنوان: (الر احة الحرارية للفر اغات التعليمية بالمباني الجامعية

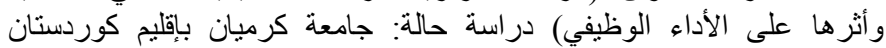

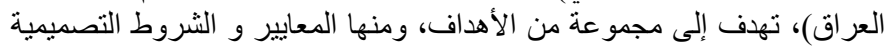

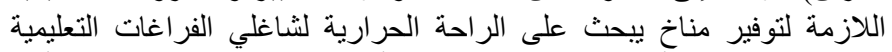

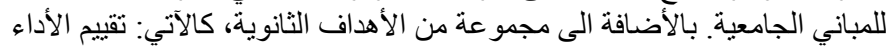

